\title{
Triple-Negative Breast Cancer: A Brief Review About Epidemiology, Risk Factors, Signaling Pathways, Treatment and Role of Artificial Intelligence
}

\author{
Nahlah Makki Almansour* \\ Department of Biology, College of Science, University of Hafr Al Batin, Hafr Al Batin, Saudi Arabia
}

Triple-negative breast cancer (TNBC) is a kind of breast cancer that lacks estrogen, progesterone, and human epidermal growth factor receptor 2 . This cancer is responsible for more than $15-20 \%$ of all breast cancers and is of particular research interest as it is therapeutically challenging mainly because of its low response to therapeutics and highly invasive nature. The non-availability of specific treatment options for TNBC is usually managed by conventional therapy, which often leads to relapse. The focus of this review is

Edited by: Abbas Khan,

Shanghai Jiao Tong University, China

Reviewed by:

Manish Charan,

The Ohio State University, United States

Daniele Fanale,

Azienda Ospedaliera Universitaria Policlinico Paolo Giaccone, Italy

${ }^{*}$ Correspondence: Nahlah Makki Almansour nahlama@uhb.edu.sa

Specialty section: This article was submitted to

Molecular Diagnostics and Therapeutics,

a section of the journal

Frontiers in Molecular Biosciences

Received: 15 December 2021 Accepted: 07 January 2022 Published: 25 January 2022

Citation: Almansour NM (2022) Triple-Negative Breast Cancer: A Brief Review About Epidemiology, Risk Factors, Signaling

Pathways, Treatment and Role of

Artificial Intelligence.

Front. Mol. Biosci. 9:836417. doi: 10.3389/fmolb.2022.836417 to provide up-to-date information related to TNBC epidemiology, risk factors, metastasis, different signaling pathways, and the pathways that can be blocked, immune suppressive cells of the TNBC microenvironment, current and investigation therapies, prognosis, and the role of artificial intelligence in TNBC diagnosis. The data presented in this paper may be helpful for researchers working in the field to obtain general and particular information to advance the understanding of TNBC and provide suitable disease management in the future.

Keywords: triple negative breast cancer, risk factor, signaling pathways, prognosis, artificial intelligence

\section{INTRODUCTION}

Breast cancer is a pathological condition that occurs in the breast tissue. In most cases, emergence occurs from the milk duct, while other minor cases occur from lobules. The cancer of the ductile region is known as ductal carcinoma, while those involving mammary lobules are called lobular carcinomas (Medina et al., 2020; Muneer et al., 2021). According to the World Health Organization (WHO) reports, breast cancer is placed second on the list of common diseases worldwide. Breast cancer has been observed to cause more mortality in the United States and Europe after lung cancer. The disease is also very common in less developed countries (Ghoncheh et al., 2016; Suleman et al., 2021).

Triple-negative breast cancers or in short TNBCs are regarded as aggressive types of breast cancer and are the product of impaired expression of progesterone and estrogen receptors as well as human growth factor receptor 2 (Bianchini et al., 2016). According to the American Society of Clinical Oncology/College of American Pathologists (ASCO/CAP) guidelines, TNBCs are typically characterized by cellular expression of progesterone and estrogen receptors of $\leq 1 \%$ and human growth factor receptor 2 expressions between 0 and 1+, as determined by immunohistochemistry (Wolff et al., 2014). There are four transcriptional subtypes of TNBCs: two basal subtypes, which are grouped as BL1 and BL2, a mesenchymal subtype M, and a luminal androgen receptor subtype 
(Lehmann et al., 2016). Further, TNBC can be categorized into six different subgroups based on their molecular heterogeneity: immunomodulatory, luminal androgen receptor expression, mesenchymal stem-like, mesenchymal-like, basal-like, and unstable (Yam et al., 2017). TNBCs constitute $12-17 \%$ of all breast cancers and are naturally recurrent. Scientifically, this cancer is categorized as a distant subgroup within a broad category of breast cancers (Foulkes et al., 2010). The clinical behavior of TNBCs is relatively aggressive compared to that of other subtypes of breast cancer. Additionally, these cancers have characteristic metastatic patterns and poor prognosis (Dent et al., 2007). TNBCs represent $24 \%$ of newly diagnosed breast cancers, and a steady increase has been reported in their incidence (Tsai et al., 2016). It has been reported that in 2018 about 2,088,849 cases of TNBC were reported making it a common cancer in women (Singh et al., 2020). The average survival rate from the disease is $\sim 10.2$ months in perspective on the currently available therapy, with a $65 \% 5$ years survival rate in cases of regional tumors and $11 \%$ for those where the tumor is spread to distant organs (Kohler et al., 2015).

In this review, the focus is to provide a comprehensive overview of TNBCs, epidemiology and risk factors, signaling pathways, prognosis, current and investigational treatment paradigm, and the role of artificial intelligence in TNBC diagnosis and treatment.

\section{EPIDEMIOLOGY OF TNBC}

TNBC accounts for 15-25\% of all breast cancers (Yin et al., 2020). The TNBC proportion in all age groups followed a similar trend (Hudis and Gianni, 2011; Khan et al., 2017). However, younger and older women have increased rates of BRCA and basal TNBC and apocrine and neuroendocrine TNBC. African American and Hispanic women are found to be at high risk of TNBC, and African Americans have a worse prognosis compared to other groups (Reynolds, 2007). In a case study conducted in 2009, 187 TNBC patients were reported to have a $2.5 \%$ higher risk for TNBC who used oral contraceptives for more than 1 year. The risk is $4.2 \%$ among women aged less than 40 years. It was also noted that when the duration of oral contraceptive use increased, the risk increased. In the United States, TNBC is responsible for $12 \%$ of breast cancers, with a 5 -years survival rate of $8-16 \%$ (Howard and Olopade, 2021).

\section{POTENTIAL RISK FACTORS}

The potential risk factors of TNBC can be divided into nonmodifiable and modifiable risk factors.

\section{NON-MODIFIABLE RISK FACTORS}

\section{Age}

Approximately $80 \%$ of breast cancers (including TNBCs) are $>50$ years old (Donepudi et al., 2014). The cancer risk increases with age as follows: $1.5 \%$ risk at the age of 40 years, $3 \%$ at age 50 , and more than $4 \%$ at age 70 years (Eukasiewicz et al., 2021). In addition, a relationship exists between cancer subtype and age. This can be explained by TNBC, which is mostly diagnosed in the age group of $<40$ years, whereas in patients aged $>70$ years, luminal A subtype cancer is more common (McGuire et al., 2015).

\section{Sex}

Due to different sex hormonal stimulation, female sex is considered a higher risk for TNBC compared to male sex. Females have breast cells that are very susceptible to estrogen and progesterone hormones, as well as imbalances. Circulation of estrogens and androgens is associated with an increased risk of breast cancer (Hormones et al., 2013). In the case of premenopausal and postmenopausal women, physiological changes in endogenous sex hormones result in a higher risk of breast cancer (Hormones and Group, 2002; Zhang et al., 2013). In men, the prevalence of breast cancer is $1 \%$. The important factors which increase a man's risk of breast cancer are; older age, "BRCA2/BRCA1" mutations, and increased estrogen levels, genetic history in family, and highly exposure to radiation (Giordano, 2018).

\section{Genetic Mutations}

Mutations in genes such as BRCA1 and BRCA2 were found to be strongly associated with TNBC (Shiovitz and Korde, 2015). Mutations in TP53, CDH1, PTEN, and STK11 are also associated with breast cancer and TNBC incidence (Corso et al., 2018; Shahbandi et al., 2020). Mutations in the XRCC2 gene are also associated with high risk of breast cancer (Kluźniak et al., 2019). Further, it has been revealed that BRCA1-related tumors profile resembles the TNBC subtype, while the profile of the BRCA2-associated tumor correlates to luminal-like breast cancers, particularly the Luminal B subtype (Incorvaia et al., 2020).

\section{Race/Ethnicity}

The incidence of TNBC remains high among white non-Hispanic women (Hill et al., 2019). In addition, the mortality rate is significantly higher among black women, and black women are considered to have the lowest survival rates for malignancy (DeSantis et al., 2016).

\section{Genetic History}

Genetic history is one of the major risk factors associated with breast cancer (similar to TNBC). Approximately 13-19\% of diagnosed breast cancer patients report a first-degree breast cancer relative (Cuzick, 2003). Moreover, the risk is higher in family members of age $<50$ years (Baglia et al., 2018). The genetic history of ovarian cancer in a family, particularly those with $B R C A 1$ and BRCA2 mutations, has a greater risk (Wu et al., 2018).

\section{Breast Tissue Density}

As per clinical practice, breast tissue density has been categorized as low-density breasts, fatty, and high-density breasts. Women 
receiving hormone replacement therapy are reported to have denser breasts during early age, during pregnancy, and breastfeeding, even with lower BMI (Titus-Ernstoff et al., 1998). In postmenopausal and premenopausal women, the density of the breast affects the risk of cancer, that is, the higher the density, the higher the chances (Checka et al., 2012). Breast tissue density screening could be a promising and quick approach for the rational surveillance (Kim et al., 2020).

\section{History of Radiation Therapy}

A history of radiotherapy can lead to the development of secondary tumors. This is mainly dependent on the patient's state and age ( $\mathrm{Ng}$ and Shuryak, 2015). Patients aged $<30$ years are considered at higher risk (Zhang et al., 2020), and radiotherapy treatments, such as multiple-field IMRT (6F-IMRT) and double partial arc (VMAT) techniques can increase the chances of secondary tumors (Balaji et al., 2016). Radiotherapy in patients with a family history of breast cancer is considered to be at a higher risk (Bartelink et al., 2001).

\section{History of Breast Diseases}

The initial symptoms of cancer are cancerous lesions in the breast (Schacht et al., 2014; Muneer et al., 2019). Regarding the family history of disease, the other risk factors associated with breast cancer are; in-situ carcinoma, atypical hyperplasia, proliferative lesions and non-proliferative lesions (Dyrstad et al., 2015; Socolov et al., 2015). Breast cancer risks include a family history of breast cancer and benign lesions (Wang et al., 2004).

\section{MODIFIABLE RISK FACTORS}

\section{Drugs}

Diethylstilbestrol is a major cause of breast cancer during pregnancy (Hoover et al., 2011). Although much more study and research is required to support this statement, diethylstilbestrol intake and consumption by pregnant women not only causes breast cancer in the mother but also the child (Hilakivi-Clarke, 2014). This relationship is observed with diethylstilbestrol uptake even without the expression of estrogen and progesterone receptors (Palmer et al., 2006). The breast cancer risk increases with an increase in diethylstilbestrol doses. Female age is another consideration, that is, the risk increases 1.9 times in women older than 40 years (Narod, 2011). Hormonal replacement therapy, when carried out for more than 5-7 years, increases the chances of breast cancer. The continuous uptake of the selective antidepressants, paroxetine, tricyclic, and serotonin inhibitors, also increases the chances of breast cancer (Cotterchio et al., 2000). Similarly, Friedman reported tetracycline can increase risk of breast cancer (Friedman et al., 2006). Furthermore, the relationship between the risk of breast cancer and excessive use of hypertensive medications, anti-inflammatory nonsteroidal drugs, and statins has also been studied, but the research data in this regard are not efficient in supporting these data (Coogan et al., 1999; Denoyelle et al., 2001).

\section{Body Mass Index}

According to several epidemiological studies, obesity is a potential risk factor for breast cancer. Epidemiologically, estrogen receptor-positive breast cancer develops in obese women in the postmenopausal period (Kolb and Zhang, 2020). However, women more than 50 years of age with greater BMI are at higher risk of breast cancer than those with low BMI (Wang et al., 2019). However, it has been reported that people with a higher BMI are at a high risk of tumors with a high percentage and size of lymph node metastasis. In premenopausal women, obesity is not only an evident cause of cancer, but also high mortality (James et al., 2015). Procarcinogenic events are facilitated by greater fat content in the body, which in turn enhances the circulation of hormones and inflammation. Females with a BMI greater than $25 \mathrm{~kg} / \mathrm{m}^{2}$ had poor clinical outcomes (Protani et al., 2010). Greater fat contents, although with the relevant BMI in post-menopausal women, have poor clinical outcomes. People with a family history of breast cancer are at a greater risk of breast cancer with greater BMI (Iyengar et al., 2019).

\section{Physical Activity}

The physical activity is considered the best action to be performed in order to prevent breast cancer (Kyu et al., 2016). This is supported by the study of Chen et al. that in women the breast cancer occurrence is reduced by physical activity during the postmenopausal period (Hormones et al., 2013), The Physical activity reduces the exposure to endogenous sex hormones and can also alter insulin-like growth factor-1 levels and immune responses (Hoffman-Goetz et al., 1998; Hormones et al., 2013).

\section{Alcohol Intake}

Various studies reported alcohol consumption is a major cause of cancer in the gastrointestinal tract, along with breast cancer (Rachdaoui and Sarkar, 2013). Alcohol and alcohol beverages can increase the risk of malignancy. The hormone balance is disturbed along with the enhanced production of estrogen, which in turn increases body weight. Alcohol and its beverages are considered to increase the risk of cancer growth (Coronado et al., 2011). Alcohols are the major causative agents of estrogenpositive breast cancers (Zeinomar et al., 2019). Morphological alterations of the breast and its tissues have been reported with the consumption of alcohol before the 1st pregnancy (Liu et al., 2015).

\section{Insufficient Vitamin Supplements}

Vitamins are anti-cancer elements that can prevent breast malignancies. Research is underway to evaluate the risk of cancer with the consumption of vitamins, particularly vitamin B, C, and E folic acids and multivitamins (Cui and Rohan, 2006). Vitamin D supplements, that is, high serum 25-hydroxyvitamin $\mathrm{D}$, are thought to be potential cancer control agents in postmenopausal women and in the premenopausal period (Atoum and Alzoughool, 2017). Excessive expression of vitamin $\mathrm{D}$ receptors is associated with a lower mortality rate in patients with breast cancer (Zhou et al., 2020). Artificial light exposure for a longer duration can increase the risk of breast 
malignancy (Al-Naggar and Anil, 2016). This occurs because of the activation of melatonin pigments and consequent epigenetic shifts (Johns et al., 2018).

\section{Exposure to Chemicals and Drugs}

Females who have been exposed to dreadful carcinogenic chemicals are at higher risk of breast cancer and epigenetic alterations and mutations. Exposure and duration of exposure contribute to an increased risk of breast cancer mutagenesis (Casey et al., 2015). Exposure of mammary glands to polychlorinated biphenyl (PCB) and dichlorodiphenyltrichloroethane (DDT) chemicals increases the risk of breast cancer (Leso et al., 2019). Furthermore, continuous exposure to organic solvents, insecticides, and oil mist increases the risk of breast cancer (Videnros et al., 2020). Antibiotics, statins, antidepressants, and antihypertensive drugs can increase the risk of breast cancer. Similarly, NSAIDs that contain aspirin and ibuprofen are considered major risk factors for breast cancer (Brandes et al., 1992; Bjarnadottir et al., 2013).

\section{Smoking}

Tobacco causes mutations in oncogenes and p53 suppressor genes (Terry and Rohan, 2002). Active smoking passive smokers are at a risk of cancer. Smoking during pregnancy and chain smokers are at potential risk of malignancies (Couch et al., 2001).

\section{Intake of Processed Food/Diet}

According to the WHO, processed foods, such as meat, are confirmed group-1 carcinogen for gastrointestinal cancer and breast malignancy (Dandamudi et al., 2018). The excessive use of saturated fats is also considered a carcinogen. The obesity-causing ultra-processed diet plans that are enriched in elements such as sugar, sodium, and fats are thought to be carcinogenic and increase the risk by $11 \%$ (Fiolet et al., 2018). Diets that are rich in green vegetables, fresh fruits, protein-enriched grains, and legumes are anti-carcinogenic and therefore reduce the risk of breast cancer (Castello et al., 2014). Similarly, diets rich in phyto-estrogen, folate elements, saturated fibers, n-3 PUFA, and vitamin D are regarded as anti-cancer agents (Dunneram et al., 2019). Hence, a low dose consumption of saturated fat and $n-6$ PUFA has been proposed (Li et al., 2014). The antioxidants found in green tea have also shown anti-carcinogenic properties (Liu and Chen, 2013). Curcuminoids and sulforaphane (SFN) derived from turmeric are thought to be anti-carcinogens (E Wright et al., 2013).

\section{Complexities of TNBC Metastasis}

TNBC is one of the most aggressive subtypes of cancer that is often associated with poor patient outcomes because of the development of metastases in secondary organisms like in the brain, bone, and lungs (Zeichner et al., 2016). Metastatic growth to these distant organs, represents a significant clinical challenge, as metastatic disease is currently incurable and is a primary death cause for the vast majority of TNBC patients. Metastatic spread of cancer is a complex, poorly understood process, and involves multiple steps, such as angiogenesis acquisition of invasive properties through epigenetic and genetic alterations, intravasation through the basement membrane, extravasation of some cancer cells to distal tissues, and tumor-stroma interactions (Nguyen and Massagué, 2007; Fatima et al., 2018). Metastatic cells outgrowth in a foreign tissue environment is considered as the rate-limiting step of breast cancer metastasis and in this stage, breast cancer cells are difficult to detect and show resistance to chemotherapy due to lack of proliferation (Giancotti, 2013; Dujon et al., 2021). To date, this remains a clinical obstacle, since the patients considered as "survivors" can develop metastatic tumors years later. Disseminated tumor cells can enter a state of dormancy in the secondary organs by achieving a balanced state of proliferation and apoptosis. Successful emergence from dormancy is the result of further evolution of surviving disseminated tumor cells by accumulating molecular changes as well as via permissive interactions with the tumor microenvironment (Giancotti, 2013). By achieving these characteristics, metastatic tumor cells can optimally adapt to the host microenvironment and initiate colonization. While significant information has been generated to identify the specific processes required for breast cancer initiation, still, much effort to elucidate the molecular mechanisms and roles of critical genes and signaling pathways involved in the late stages of metastatic growth are required.

\section{SIGNALING PATHWAYS}

\section{Notch Signaling Pathway}

The term Notch was first described by Thomas Hunt Morgan in 1917 and refers to transmembrane receptors and ligands (Gu et al., 2016; Fatima et al., 2018). This juxtacrine signaling pathway plays a central role in the developmental process and uses communication among cells via transmembrane interactions with ligands (Yaron et al., 2014). The Notch pathway is a short-range cell-to-cell communication pathway that is critical for metazoan development (Artavanis-Tsakonas et al., 1999). The Notch receptor is expressed on the plasma membrane and cleaved by furin-like convertase in the Golgi compartment (Blaumueller et al., 1997). The Notch pathway has been identified in Drosophila melanogaster. From a structural perspective, Notch receptors share three domains: an intracellular domain, a transmembrane region, and an extracellular domain (Bellavia et al., 2008). This signaling pathway is key in cell proliferation and differentiation (Palomero et al., 2006) most importantly, governs embryonic development and maintains tumor stemness to TNBC tumor metastasis. There are four Notch receptors and five ligands in this pathway. The receptors can be named as Notch 1 to 4 , while ligands are Delta-like 1, Delta-like 3, Delta-like 4, Jagged-1, and Jagged-2 (Speiser et al., 2013). Several reports have indicated the overexpression of Jagged 1 and Delta 1 in breast cancer. The Notch 1 is involved in pancreatic cancer and hematological malignancies, while Notch-3/4 has been found to assist in tumor proliferation and survival. Notch-2 overexpression in TNBC appears to play a protective role (Weijzen et al., 2002). Notch expression has been linked to TNBCs, and scientists believe that targeting receptors by monoclonal antibodies can 


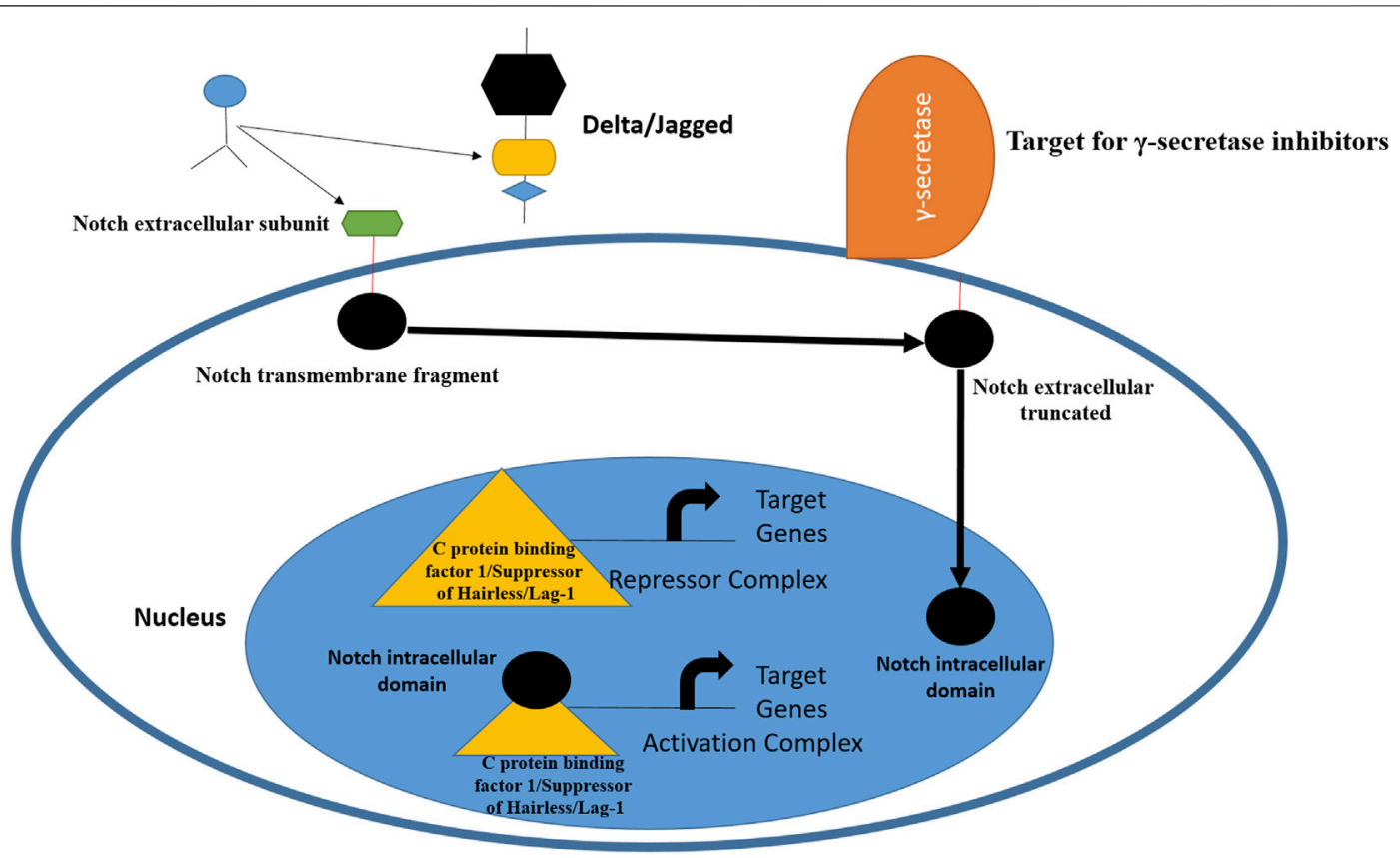

FIGURE 1 | Schematic representation of Notch receptor activation and avenues for therapeutic intervention. The pathway is activated by ligand binding to Notch receptor, followed by proteolytic cleavage fy proteases. This releases the Notch intracellular domain, which is then transferred to nucleus for biding with $\mathrm{C}$ protein binding factor 1/Suppressor of Hairless/Lag-1 allowing conversion of complex from repressor to activator of Notch genes. From inhibition perspective, $\gamma$-secretase inhibitors and monoclonal antibodies can inhibit Notch ligands and receptors (Yuan et al., 2015; Medina et al., 2020).

reduce HES and HEY-L families (Sharma et al., 2012). The monoclonal antibody based on the delta-like ligand 4 Notch ligand also showed effectiveness in treating TNBC (Benedito et al., 2009). Inhibitors that target the Notch signaling pathway act at proteolytic cleavage and block the formation of multimeric $\gamma$-secretase complexes; thus, these drugs are termed $\gamma$ secretase inhibitors (Chan et al., 2007). The Notch pathway and the points at which it can be blocked are shown in Figure 1.

\section{Wnt/ $\beta$-Catenin Pathway}

Different Wnt ligands, such as WNT3A, WNT11, and WNT5A, are reported to be pertinent in cancer migration and invasion (Zhu et al., 2012). In particular, the FZD6 receptor is associated with increased malignant cell motility in TNBC (Corda et al., 2017). It has been revealed that OMP-18R5 antibody targets Frizzled receptors to diminish tumor cell proliferation in colon, lung, breast, and pancreatic tumors (Gurney et al., 2012). Wnt/ $\beta$ catenin signaling pathway is activated in epithelial ovarian cancer and targets gene regulate cell proliferation and apoptosis thereby mediating cancer initiation and progression. Furthermore, Wnt inhibitors can destroy drug-resistant cells and cancer stem cells (Dean et al., 2005).

\section{TGF- $\beta$ Signaling Pathway}

TGF-beta 1 is expressed exponentially in TGF- $\beta 1$ and TGF- $\beta 1$ and has been implicated in its important role in breast cancer stem cells (Jamdade et al., 2015). In vivo analysis, inhibition of TGF- $\beta$ leads results in multiplication and growth of tumor cells. The frequent overexpression of TGF- $\beta$ in the TNBC tumor microenvironment, particularly in stromal, tumor-associated immune cells, and tumor cells. In these cells, SMAD4 and SMAD2/3 cause metastasis and angiogenesis (Bhola et al., 2013). Thus, inhibition of TGF- $\beta$ plays a significant therapeutic role in patients with metastasis.

\section{Signaling Pathway of CSPG4 Protein}

The CSPG4 protein (non-glial antigen) is expressed as a cell surface proteoglycan by basal breast carcinoma cells. Therapeutically, CSPG4 inhibition allows for efficient management of breast cancer (Wang et al., 2010). Monoclonal antibodies can block the CSPG4 protein, which hinders survival signaling pathways in tumor cells. In addition, controlling the overexpression of CSPG4 by targeting it therapeutically is seen in different TNBC cells (Cooney et al., 2011).

\section{Hedgehog Signaling Pathway}

The Hedgehog signaling pathway is involved in cancer cell invasion, metastasis, drug resistance, and tumor recurrence ( $\mathrm{Li}$ et al., 2012). Overexpression of this pathway results in poor prediction of breast cancer mortality, especially in TNBC patients. The Hedgehog signaling pathway is considered to initiate breast cancer malignancy. Thiostrepton is a novel experimental drug that suppresses TNBC $\mathrm{CD} 44^{+} / \mathrm{CD} 24^{-}$ cancer stem cells (Yang et al., 2016).

\section{PI3K/AKT/mTOR Pathway}

Rapamycin and paclitaxel drugs are used to inhibit the PI3K/ $\mathrm{AKT} / \mathrm{mTOR}$ pathway and hence play a significant role in TNBC 


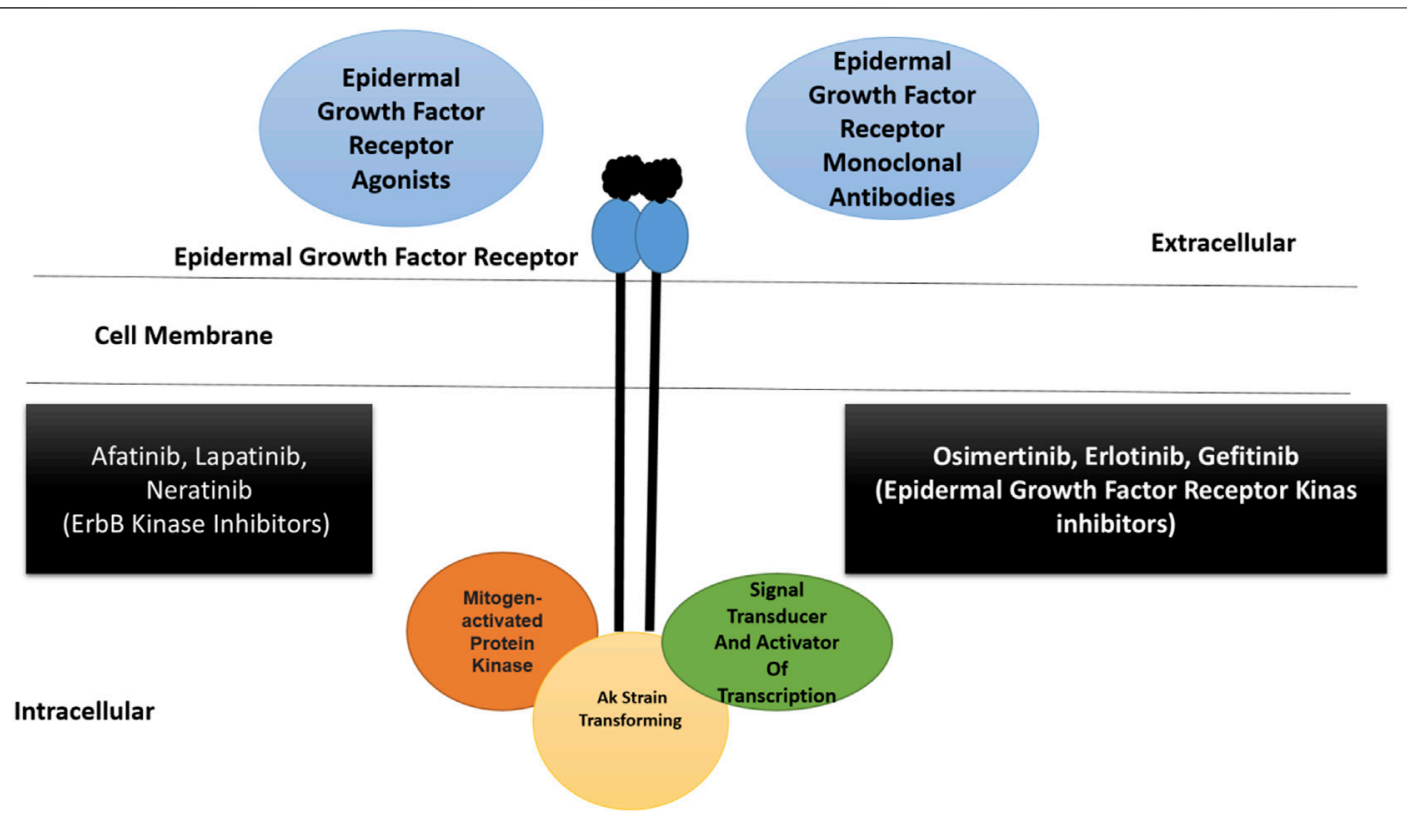

FIGURE 2 | A schematic illustration of epidermal growth factor receptor signaling pathway along with activators and inhibitors. The pathway is part of ErbB superfamily. The epidermal growth factor receptor is able to bind to different ligands at the extracellular surface resulting in the activation of downstream signaling events. Therapeutics including monoclonal antibodies and different kinase inhibitors can block the binding of ligand to the receptor. The kinase inhibitors can also block the function of other ErbB receptors (Ali and Wendt, 2017; Medina et al., 2020). Inhibitors of polyadenosine diphosphate-ribose polymerase.

treatment. Furthermore, mTOR antibodies are considered more effective than mTOR inhibitors alone (Ali and Wendt, 2017). In TNBC patients, ipatasertip (an AKT inhibitor) can promote progression-free survival by inactivating the PI3K/AKT pathway. Despite these efforts on PI3K/AKT/mTOR pathway inhibitors, synthesis of novel inhibitors is needed to block the $\mathrm{PI} 3 \mathrm{~K} / \mathrm{Akt} / \mathrm{mTOR}$ pathway and act as therapeutic agents against TNBC (Blanco et al., 2014).

\section{Epidermal Growth Factor Receptor}

The epidermal growth factor receptor is reported in $89 \%$ of TNBC and is considered an attractive therapeutic target, particularly in BL2 subtype tumors (Sobande et al., 2015). The expression of this gene results in primary tumorigenesis and metastasis. The EGFR inhibitor gefitinib lowers the proliferation of cancer cells and increases carboplatin and docetaxel cytotoxicity (Eccles, 2011). Several EGFR inhibitors, such as lapatinib and erlotinib, are currently being tested against TNBC, in addition to cetuximab and panitumumab (monoclonal antibodies) (Nabholtz et al., 2014; Hsiao et al., 2015). The synergistic therapeutic approach of monoclonal antibodies and chemotherapeutics is considered to be more effective. This can be exemplified by the combined use of carboplatin and cetuximab, and cisplatin and cetuximab proved to be more efficacious in patients with advanced TNBC (Carey et al., 2012). Additionally, tri-inhibitor therapy, including carboplatin, gefitinib, and docetaxel, enhances TNBC cytotoxicity. Cannabidiol inhibits breast cancer metastasis by interfering with the epidermal growth factor pathway (Velasco et al., 2016). The epidermal growth factor receptor signaling pathway is presented along with activator and inhibitor points of action, as shown in Figure 2.

Polyadenosine diphosphate-ribose polymerase is involved in molecular mechanisms that allow cells to recover from DNA damage, apoptosis, gene transcription, and genomic stability (Park and Chen, 2012). In approximately 70 and 23\% of breast cancers, BRCA1 and BRCA2 mutations have been reported (Mahfoudh et al., 2019). For both these mutations and TNBC, PARP inhibitors are regarded as the most vital drugs. The activation of PARP-1 and PARP-2 proteins is a consequence of DNA strand breaks. The polyadenosine diphosphate-ribose polymerase enzyme is synthesized by PARP and drives the single-strand break repair and excision repair pathway (De Vos et al., 2012). It has been observed that when PARP activity is affected, it blocks DNA polymerase $\varepsilon$ for DNA damage repair (Helleday, 2011). Veliparib and olaparib are both PARP inhibitors that have different catalytic inhibition mechanisms (Murai et al., 2012). The inhibition of poly (ADP-ribose) polymerase in BRCA-1/2-associated and sporadic cancers is shown in Figure 3.

\section{Mammalian Target of Rapamycin}

The mTor pathway is responsible for poor prognosis due to the aggressive nature of the cancer and its good tissue invasion property (Xie et al., 2016). Errors in the mTOR pathway are strongly correlated with malignancy (Fruman and Rommel, 


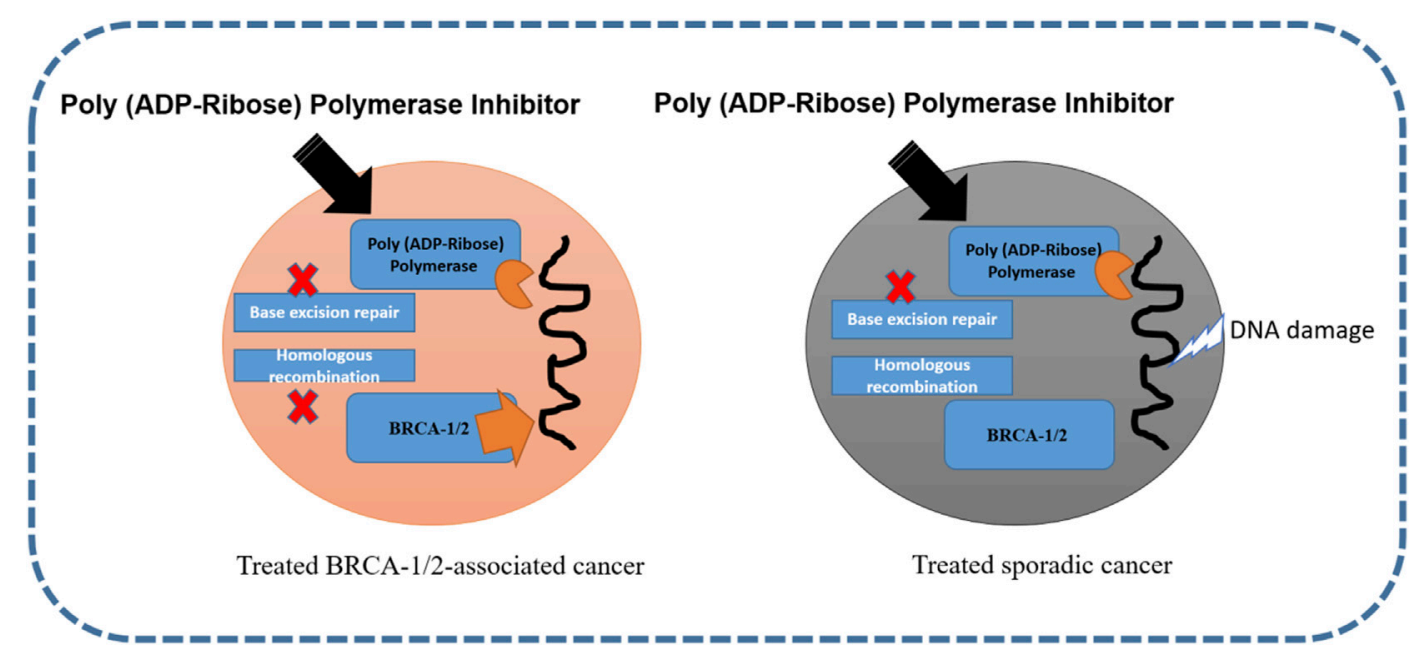

FIGURE 3 | Inhibition of poly (ADP-ribose) polymerase in BRCA-1/2-associated and sporadic cancers (Ellisen, 2011; Medina et al., 2020).

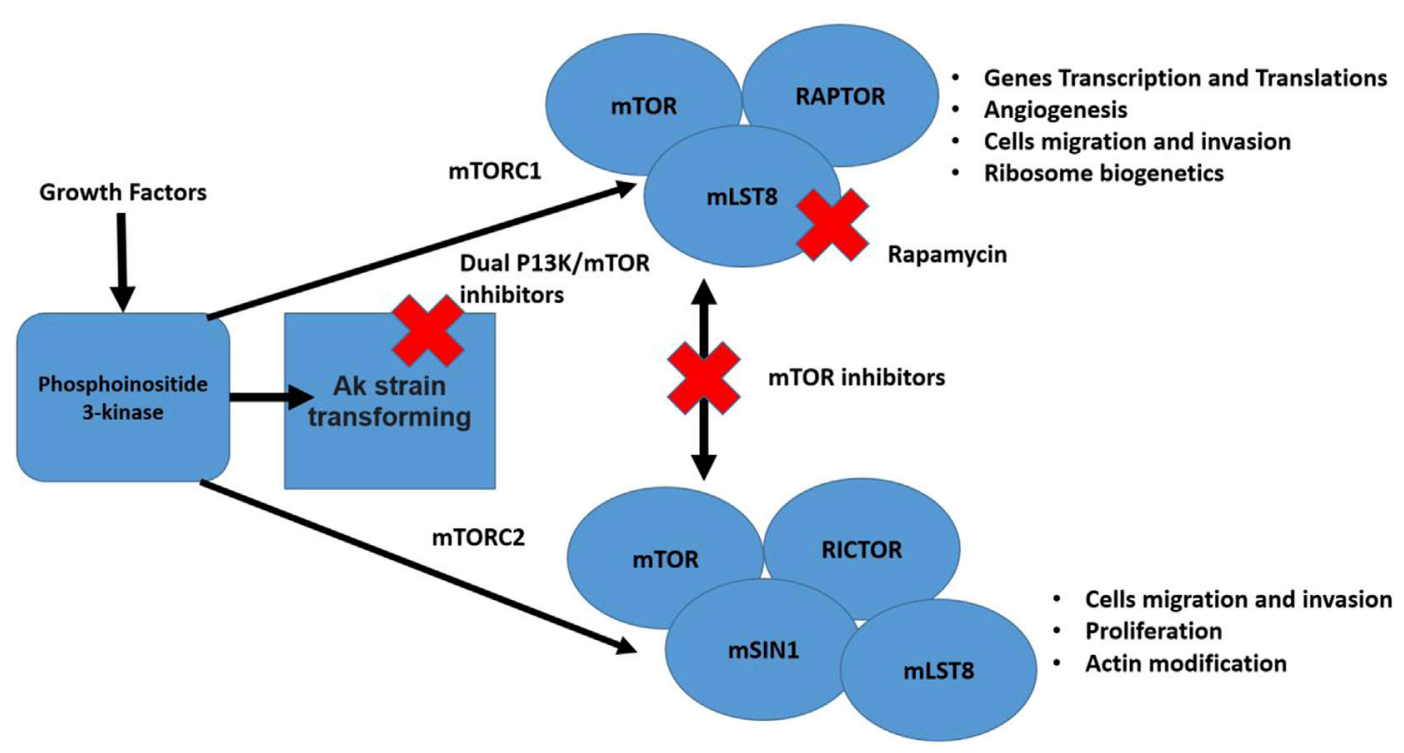

FIGURE 4 | The mTor pathway illustrating two distinct complexes (mTORC1 and mTORC2). The pathway is stimulated by different growth factors. The mTORC2 activated Akt. Multiple cell functions are regulated by both mentioned complexes that are considered vital for cancer development. Also, in the figure different steps of the pathway that can be blocked by inhibitors are shown (Xie et al., 2016; Medina et al., 2020).

2014). The phosphorylation reactions of this pathway are also associated with proliferation, vascular endothelial growth factor, and angiogenesis, that enhance endothelial cell growth (Arcaro and Guerreiro, 2007). Moreover, high expression of a protein kinase enzyme (Akt) has been reported to be involved in tumor invasion and metastasis therefore, inhibiting the mTOR pathway can be an efficient anti-cancer strategy for several human malignancies (Xie et al., 2016). In general, inhibitors of the $\mathrm{PI} 3 \mathrm{~K} / \mathrm{AKT} / \mathrm{mTOR}$ network can be grouped as: 1) AKT blockers, 2) Pan-PI3K/mTOR blocker, 3) PI3K blocker, 4) Rapalogs (temsirolimus, everolimus, and deforolimus), and 5)
mTOR blocker (Xie et al., 2016). The mTor pathway and checkpoints where it can be blocked are presented in Figure 4.

\section{Immunosuppressive Immune Cells in the TNBC Tumor Microenvironment}

The tumor microenvironment (TME) involves the surrounding blood vessels, fibroblasts, immune cells, signaling molecules and the extracellular matrix around the tumor (Deepak et al., 2020). Tumor Infiltrating Lymphocytes (TILs) produce endogenous antitumor immune response for inhibiting tumor progression 
TABLE 1 | Conventional treatment option for TNBC.

\begin{tabular}{|c|c|c|c|}
\hline Treatment & TNBC Type & Drugs & References \\
\hline Neo-adjuvant Therapy & Early TNBC, Advanced or Metastatic & $\begin{array}{l}\text { Capecitabine + Taxane } \\
\text { Anthracyclines + Taxanes } \\
\text { Capecitabine + Ixabepilone } \\
\text { /Ixabepilone monotherapy }\end{array}$ & Ali and Wendt, (2017) \\
\hline $\begin{array}{l}\text { New } \\
\text { Neo-adjuvant agents }\end{array}$ & BRCA mutations & Nab-paclitaxel, evacizumab, Carboplatin & Sikov et al. (2015) \\
\hline Adjuvant agents & Early TNBC & Taxanes and Anthracyclines & Martin et al. (2013) \\
\hline
\end{tabular}

and improving free survival rate of TNBC patients (Reis-Filho and Tutt, 2008; Yu and Di, 2017). Tumor associated macrophages are important for immunosuppressive role by secreting inhibitory cytokines, regulatory $\mathrm{T}$ cells infiltration promotion, and reactive oxygen species reduction (Yu and Di, 2017). Cancer-Associated Fibroblasts lower anti-tumor immunity, favor tumor cell proliferation and invasion and reshape the extracellular matrix (Yu and Di, 2017). Tumor associated neutrophils aid in lysing tumor cells and induce antitumor function (Annaratone et al., 2020).

\section{Existing and Investigational Treatment Paradigm}

From a chemotherapeutic perspective, TNBC is very sensitive, and treatments require extreme care. Common treatment involves the use of alkylating agents (such as cyclophosamide), anthracycline (doxorubicin topoisomerase blocker and DNA intercalating agents), anti-metabolite fluorouracil, and antimicrotubule agent (taxane) (Chang et al., 2019; Won and Spruck, 2020). For early diagnosis of TNBC, neoadjuvant chemotherapy and subsequent surgery are applied. No standard chemotherapy has been described for the treatment of relapsed TNBC. Treating advanced TNBC includes the following drugs: gemcitabine and capecitabine (antimetabolites), eribulin (non-taxane microtubule inhibitor), and platinum (DNA cross-linker). The conventional treatment options for TNBC are listed in Table 1.

For advanced TNBC, new therapies have been reported, particularly when surgery is not desired. Compared to other breast cancer subtypes, TNBCs show greater immunogenicity. They have tumor-infiltrating lymphocytes in their microenvironment and express programmed cell death ligand (PD-L1) in high order (Stanton et al., 2016). Considering the therapeutic potential of the PD-L1 pathway, several immunotherapies have been explored, and atezolizumab combined with nanoparticle albumin-bound paclitaxel has been approved by the US FDA as the first-line therapy in 2019 (Schmid et al., 2018). Pembrolizumab was approved in 2017 as an anti-PD-1 antibody (Dudley et al., 2016). In 2018, talazoparib and olaparib were approved by the FDA for treating HER2 negative breast cancer (Won and Spruck, 2020). With the aim of improving TNBC treatment, several therapeutic strategies have been explored in clinical studies, including those that target or are immune specific for tumor stroma, intracellular or surface receptors, DNA damage response, and signaling pathways. So far,
399 studies have been shown on ClinicalTrials. gov for TNBC and are under phase III investigation (Ahmed et al., 2014; Riaz et al., 2017; Won and Spruck, 2020). The concept of immune checkpoint inhibitors is to halt regulatory immune checkpoints and thus activate anti-tumor responses. This treatment strategy is considered a game changer in cancer therapy and involves molecules that can negatively alter the immune response. Immune checkpoints can be readily blocked by antibodies or modified by recombinant ligands (Pardoll, 2012; Muneer et al., 2021). Immune checkpoint inhibitory antibodies aid in the attachment of molecules capable of stopping the immune response to tumor-infiltrating lymphocytes, leading to reactivation of antitumor immune responses (Singh et al., 2021). Research regarding the use of immune checkpoint inhibitor(s) either alone as a single agent or in combination therapy is ongoing (Adams et al., 2019). Neoadjuvant therapy has yielded mixed results. Promising anti-tumor activity and considerable safety were noted when neoadjuvant chemotherapy was used in combination with pembrolizumab in early stage TNBC (Nanda et al., 2020). In one study, neoadjuvant combination therapy revealed a higher pathologic complete response rate (65\%) than the placebo-chemotherapy group (61\%). In another study, neoadjuvant chemotherapy was investigated with or without atezolizumab for early stage and high-risk unilateral breast cancer. However, no improvement was seen in the pathologic complete response using the combination therapy (Gianni et al., 2019). Immunotherapy involving targeting of the $2 \mathrm{~B}$ receptor $\left(\mathrm{A}_{2 \mathrm{~b}} \mathrm{R}\right)$ and adenosine $2 \mathrm{~A}$ receptor $\left(\mathrm{A}_{2 \mathrm{a}} \mathrm{R}\right)$ is considered a promising approach for the reactivation of antitumor immunity and enhancement of cytotoxic $\mathrm{T}$ cell immune responses (Ohta, 2016). In different clinical trials, the combination of immune checkpoint inhibitors and adenosine pathway inhibitors has been investigated. For example, NZV930, which is an anti-CD72 antibody when used alone or in combination with a PD-1 inhibitor or $\mathrm{A}_{2 \mathrm{a}} \mathrm{R}$ antagonist to block adenosine mediated inhibition of $\mathrm{T}$ lymphocytes. In another ongoing study, NIR178 was used in combination with spartalizumab for diffuse large B-cell lymphoma and multiple solid tumors to check whether the addition of an antagonist improves PD-1 inhibition efficacy. In addition, AB928 (a dual adenosine $\mathrm{A}_{2 \mathrm{a}} \mathrm{R} / \mathrm{A}_{2 \mathrm{~b}} \mathrm{R}$ receptor antagonist) is being evaluated in combination with AB122 (PD-1 inhibitor) for patients with advanced malignancies (Powderly et al., 2019). Different types of poly (ADP-ribose) polymerase inhibitors have also been described. These inhibitors include niraparib, veliparib, olaparib, talazoparib, and rucaparib (Won and Spruck, 2020). 
TABLE 2 | Different types of nano medicines under experimental and clinical testing for TNBC theranostics (Medina et al., 2020).

\begin{tabular}{|c|c|c|c|}
\hline Nanoparticle & Status & Therapeutic applications & References \\
\hline $\begin{array}{l}\text { Fluorescent nano- } \\
\text { diamonds }\end{array}$ & $\begin{array}{l}\text { Experimental and under clinical } \\
\text { testing }\end{array}$ & $\begin{array}{l}\text { It uses non-radioactive materials for imaging and has enhanced } \\
\text { specificity and sensitivity }\end{array}$ & Fudala et al. (2013) \\
\hline Quantum dots & $\begin{array}{l}\text { Experimental and under clinical } \\
\text { testing }\end{array}$ & Quantitative detection and cancer imaging & $\begin{array}{l}\text { (Michalet et al., 2005; Zheng } \\
\text { et al., 2016) }\end{array}$ \\
\hline Silver nanoparticles & $\begin{array}{l}\text { Experimental and under clinical } \\
\text { testing }\end{array}$ & Cytotoxicity to cancer cells & Swanner et al. (2015) \\
\hline $\begin{array}{l}\text { Superparamagnetic iron } \\
\text { oxide } \\
\text { nanoparticles }\end{array}$ & $\begin{array}{l}\text { Experimental and under clinical } \\
\text { testing }\end{array}$ & Induce tumor apoptosis & Vyas et al. (2015) \\
\hline Iron oxide nanoparticles & $\begin{array}{l}\text { Experimental and under clinical } \\
\text { testing }\end{array}$ & Produce contrasting images in MRI & Hayashi et al. (2013) \\
\hline Gold nano-stars & $\begin{array}{l}\text { Experimental and under clinical } \\
\text { testing }\end{array}$ & Drug delivery, hyperthermia, theranosics and gene therapy & Zhang et al. (2021) \\
\hline Core-shell nanoparticles & $\begin{array}{l}\text { Experimental and under clinical } \\
\text { testing }\end{array}$ & Generate apoptosis & Meng et al. (2018) \\
\hline Nanocages & $\begin{array}{l}\text { Experimental and under clinical } \\
\text { testing }\end{array}$ & Hyperthermia, Immunotherapy, theranostics, and photodynamics & Liang et al. (2018) \\
\hline Nanocomposites & $\begin{array}{l}\text { Experimental and under clinical } \\
\text { testing }\end{array}$ & $\begin{array}{l}\text { Hyperthermia, Immunotherapy, theranostics, drug delivery and } \\
\text { photodynamics }\end{array}$ & Liao et al. (2019) \\
\hline Nanorods & $\begin{array}{l}\text { Experimental and under clinical } \\
\text { testing }\end{array}$ & $\begin{array}{l}\text { Hyperthermia, Immunotherapy, gene therapy, theranostics, drug } \\
\text { delivery and photodynamics }\end{array}$ & Feng et al. (2015) \\
\hline
\end{tabular}

The role of androgen receptor inhibitors in TNBC still needs to be explored, and more insights need to be explored. The firstgeneration androgen receptor antagonist bicalutamide is a proof of concept for treating advanced TNBC, and the results showed a modest clinical benefit rate of 19\% (Gucalp et al., 2013). Abiraterone, a second-generation anti-androgen inhibitor, shows promising targeting of androgen biosynthesis (Bonnefoi et al., 2016). Another second-generation androgen receptor inhibitor, enzalutamide, showed competitive binding to the androgen receptor ligand-binding domain and blocked its nuclear translocation, coactivator recruitment, and DNA binding (Traina et al., 2018). Seviteronel targets estrogen and androgen production (Gucalp et al., 2017). In addition to these therapeutic options, cell surface targets, such as tumor-associated carbohydrate antigens, have been explored as antigens for vaccine formulation. In particular, the Globo $\mathrm{H}$ antigen, which is expressed on the surface of different cancer types, can be explored for vaccine design. Adagloxad simolenin is an immunostimulating agent consisting of a Globo $\mathrm{H}$ hexasaccharide epitope fused with a keyhole limpet hemocyanin protein carrier (Gilewski et al., 2001). The antibody-drug conjugate remains stable in plasma, attacking antigens at the tumor cell surface with high specificity and affinity, followed by internalization, cleavage, and release of the payload drug to exert anti-tumor activity. For example, Sacituzumab govitecan-hziy targets human trophoblast cellsurface antigen 2, which is present in more than $90 \%$ of TNBCs. In this case, the active metabolite is irinotecan in conjugation with anti-trophoblast cell-surface antigen 2 antibody (Bardia et al., 2019). Ladiratuzumab vedotin or a short LV main target is a transmembrane protein (LIV-1). The protein has metalloproteinase and zinc transporter activity and is expressed in more than $90 \%$ of breast tumors. Ladiratuzumab vedotin comprises the microtubule-disrupting agent monomethyl auristatin $\mathrm{E}$ as payload (Bonnefoi et al., 2016). In addition to these therapeutic strategies against TNBCs, new platforms have been described. In this approach, $\mathrm{EZH} 2$ inhibitors were evaluated against the CDK2-EZH2 axis, thus reactivating ERa expression (Nie et al., 2019). In a recent study, researches combined the PARP inhibitor with CSF-1R blocking antibodies to elucidate the key contribution of immunosuppression to limiting the effective anti-tumor response their study demonstrates that combining the PARP inhibition with macrophage targeting therapy induces a durable reprograming of the tumor microenvironment and can be used as a promising therapeutic strategy for TNBC (Mehta et al., 2021). In another new technique, the combination of histone deacetylase and DNA methyltransferase inhibitor results in ERa expression in breast cancer models (Yang et al., 2001). The different types of nanomedicines under experimental and clinical testing for TNBC theranostics are tabulated in Table 2.

\section{Targeting Tumor Microenvironment for TNBC Therapy}

The development of TNBC has strong association with the physiological state of TME. TNBC has been characterized with unique TME and is different from other subtypes (RomaRodrigues et al., 2019). TME has strong association with induction of angiogenesis, proliferation, apoptosis inhibition, suppression of immune system and resistance to drugs (Kuroda et al., 2021). The exosomes function as promising nanovesicles that directs TME orchestration by communicating cells within TME milieu (Deepak et al., 2020). 


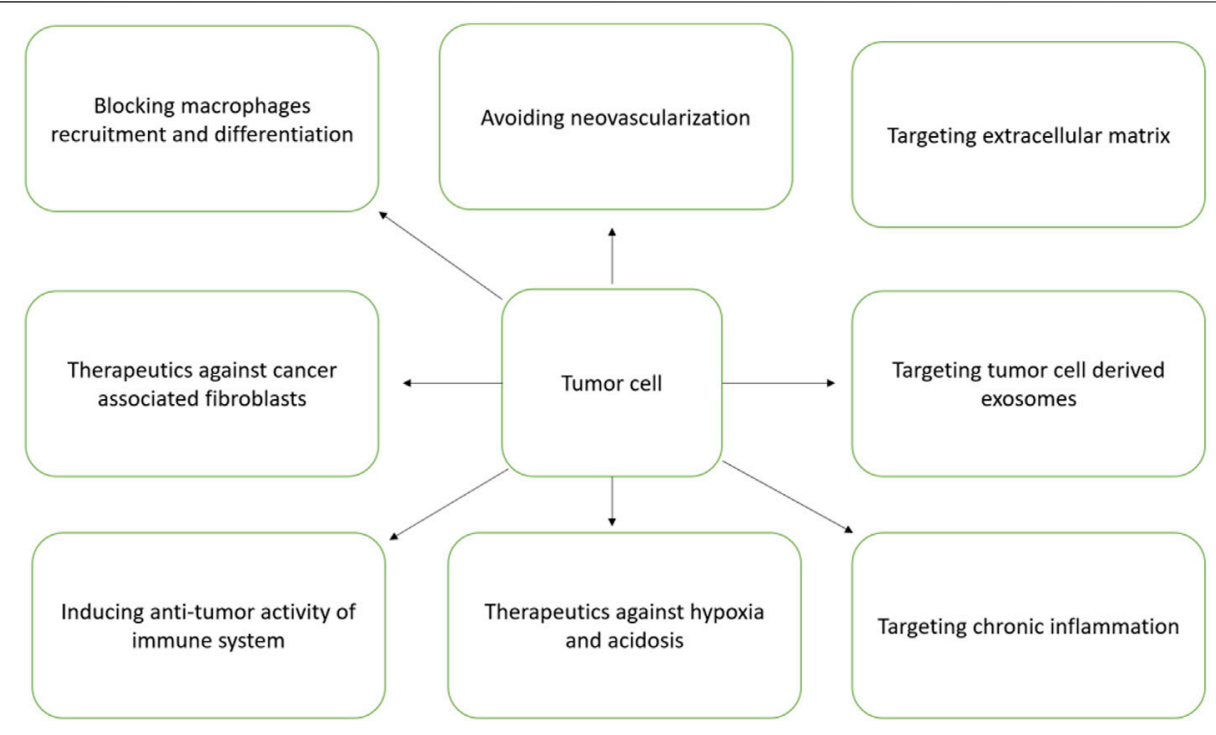

FIGURE 5 | Different TME targets for therapeutic intervention.

The different components of TME particularly the soluble factors, transformed extracellular matrix, immune suppressive cells, reprogrammed fibroblasts and epigenetic modifications altogether helps in TNBC progression and metastasis (Deepak et al., 2020). Hence, TME is regarded as a good therapeutic target. The different TME targets for therapeutic intervention is schematically presented in Figure 5.

\section{Prognosis of TNBC}

The prognostic research of TBNC is mostly performed as retrospective studies, and these studies considered diagnostic data. Most of these studies used the triple negativity inclusion factor and neglected molecular markers for basal-like breast cancer. Poor prognosis has been observed in patients with TNBC (Nofech-Mozes et al., 2009). In contrast to other subtypes, TNBC development occurs more frequently in premenopausal women during early life. TNBC has a more aggressive expression profile (high p54 and Ki67 and low Bcl2 expression), large tumor size, and high nuclear mitotic grade (Rhee et al., 2008). Many studies have demonstrated lower RFS in TNBC than in non-TNBC patients. The 4-year survival rate of TNBC patients was $85.5 \%$, which is comparable to that of nonTNBC patients (94.2\%) (Rhee et al., 2008). In another study, relapse frequency was less frequently reported in TNBC (Parikh et al., 2008). Tumor recurrence is 1.2 years which is shorter than that in non-TNBC patients. Similarly, TNBC has a worse prognosis in patients with recurrent breast cancers. The risk of tumor recurrence and death is high in TNBC, in contrast to the other types. It has been reported that the hazard ratio (HR 4.2 for developing TNBC tumor recurrence when compared to other cancers (Mersin et al., 2008). For triple-positive breast cancer, the 5 year survival is $91 \%$, whereas for TNBC and HR-positive/ HER2-negative cancers, it is 81 and 94\%, respectively, (Kaplan and Malmgren, 2008).
Artificial Intelligence in TNBC Management In the last decade, the power of artificial intelligence in different scientific fields, particularly in medicine, has been seen as a real tool for the efficient diagnosis and management of diseases. Artificial intelligence-based applications in medical sciences include computer-aided detection and diagnosis of diseases, case-based reasoning, explainable artificial intelligence, osteodetect machine learning, and rainbox boxes (Wang et al., 2018). Decision Support and Information Management System for Breast Cancer (DESIREE) is a product of artificial intelligence that can be used in cancer prediction and interpretation of clinical data. Different artificial intelligence-based tools are also used for breast cancer screening. The metadata, which serve as the basis of these artificially based algorithm designs, are provided by the cancer data bank along with patient biodata history and treatment trends. The data are analyzed both quantitatively and qualitatively to train the algorithms so that the tools/ servers can assist physicians in faster and more accurate ways to detect and manage complex cancer types. Recently, Fernández Martínez et al. reported a machine-learning algorithm that is capable of detecting different TNBC subtypes. The Cancer Genome Atlas (TCGA) is another platform that collects SNP data, DNA and RNA sequence data, and reserve phase protein array information. Together with the Molecular Taxonomy of the Breast Cancer International Consortium (METABRIC), TCGA aims to provide data related to molecular heterogeneity of different breast cancer subtypes. Both databases could help oncologists in advising personalized medicine for cancer patients in a timely manner. Very limited work has been done so far in this field, and much more interdisciplinary efforts are required to put solid platforms that cannot easily diagnose TNBC early, but at the same time allow efficient and effective treatment. 


\section{CONCLUSION}

Among all breast cancers, TNBC has the worst prognosis, in addition to suppressed immunity of the patient. Hence, understanding the TNBC molecular signaling pathway in the tumor microenvironment by applying multidisciplinary research will greatly advance TNBC diagnosis and therapy. In-depth information of TNBC pathways at the genetic and proteomic levels can assist in novel therapeutic design and

\section{REFERENCES}

Adams, S., Gatti-Mays, M. E., Kalinsky, K., Korde, L. A., Sharon, E., AmiriKordestani, L., et al. (2019). Current Landscape of Immunotherapy in Breast Cancer. JAMA Oncol. 5, 1205-1214. doi:10.1001/jamaoncol.2018.7147

Ahmed, B., Ashfaq, U. A., Qamar, M. T. u., and Ahmad, M. (2014). Anticancer Potential of Phytochemicals against Breast Cancer: Molecular Docking and Simulation Approach. Bangladesh J. Pharmacol. 9. 545-550. doi:10.3329/bjp. v9i4.20412

Al-Naggar, R. A., and Anil, S. (2016). Artificial Light at Night and Cancer: Global Study. Asian Pac. J. Cancer Prev. 17, 4661-4664. doi:10.22034/apjcp.2016.17.10. 4661

Ali, R., and Wendt, M. K. (2017). The Paradoxical Functions of EGFR during Breast Cancer Progression. Signal. Transduct. Target. Ther. 2, 1-7. doi:10.1038/ sigtrans.2016.42

Annaratone, L., Cascardi, E., Vissio, E., Sarotto, I., Chmielik, E., Sapino, A., et al. (2020). The Multifaceted Nature of Tumor Microenvironment in Breast Carcinomas. Pathobiology 87, 125-142. doi:10.1159/000507055

Arcaro, A., and Guerreiro, A. (2007). The Phosphoinositide 3-kinase Pathway in Human Cancer: Genetic Alterations and Therapeutic Implications. $\mathrm{Cg} 8$, 271-306. doi:10.2174/138920207782446160

Artavanis-Tsakonas, S., Rand, M. D., and Lake, R. J. (1999). Notch Signaling: Cell Fate Control and Signal Integration in Development. Science 284, 770-776. doi:10.1126/science.284.5415.770

Atoum, M., and Alzoughool, F. (2017). Vitamin D and Breast Cancer: Latest Evidence and Future Steps. Breast Cancer (Auckl) 11, 1178223417749816. doi:10.1177/1178223417749816

Baglia, M. L., Tang, M.-T. C., Malone, K. E., Porter, P., and Li, C. I. (2018). Family History and Risk of Second Primary Breast Cancer after In Situ Breast Carcinoma. Cancer Epidemiol. Biomarkers Prev. 27, 315-320. doi:10.1158/ 1055-9965.epi-17-0837

Balaji, K., Subramanian, B., Yadav, P., Anu Radha, C., and Ramasubramanian, V. (2016). Radiation Therapy for Breast Cancer: Literature Review. Med. Dosimetry 41, 253-257. doi:10.1016/j.meddos.2016.06.005

Bardia, A., Mayer, I. A., Vahdat, L. T., Tolaney, S. M., Isakoff, S. J., Diamond, J. R., et al. (2019). Sacituzumab Govitecan-Hziy in Refractory Metastatic TripleNegative Breast Cancer. N. Engl. J. Med. 380, 741-751. doi:10.1056/ nejmoa1814213

Bartelink, H., Horiot, J.-C., Poortmans, P., Struikmans, H., Van den Bogaert, W., Barillot, I., et al. (2001). Recurrence Rates after Treatment of Breast Cancer with Standard Radiotherapy with or without Additional Radiation. N. Engl. J. Med. 345, 1378-1387. doi:10.1056/nejmoa010874

Bellavia, D., Checquolo, S., Campese, A. F., Felli, M. P., Gulino, A., and Screpanti, I. (2008). Notch3: from Subtle Structural Differences to Functional Diversity. Oncogene 27, 5092-5098. doi:10.1038/onc.2008.230

Benedito, R., Roca, C., Sörensen, I., Adams, S., Gossler, A., Fruttiger, M., et al. (2009). The Notch Ligands Dll4 and Jagged1 Have Opposing Effects on Angiogenesis. Cell 137, 1124-1135. doi:10.1016/j.cell.2009.03.025

Bhola, N. E., Balko, J. M., Dugger, T. C., Kuba, M. G., Sánchez, V., Sanders, M., et al. (2013). TGF- $\beta$ Inhibition Enhances Chemotherapy Action against TripleNegative Breast Cancer. J. Clin. Invest. 123, 1348-1358. doi:10.1172/jci65416

Bianchini, G., Balko, J. M., Mayer, I. A., Sanders, M. E., and Gianni, L. (2016). Triple-negative Breast Cancer: Challenges and Opportunities of a successful trial development. New developments in computer biology and discoveries in immunology, nanotechnology, and molecular biology will ease earlier diagnosis and personalized treatment.

\section{AUTHOR CONTRIBUTIONS}

\author{
NA planned, performed and write whole review.
}

Heterogeneous Disease. Nat. Rev. Clin. Oncol. 13, 674-690. doi:10.1038/ nrclinonc. 2016.66

Bjarnadottir, O., Romero, Q., Bendahl, P.-O., Jirström, K., Rydén, L., Loman, N., et al. (2013). Targeting HMG-CoA Reductase with Statins in a Window-OfOpportunity Breast Cancer Trial. Breast Cancer Res. Treat. 138, 499-508. doi:10.1007/s10549-013-2473-6

Blanco, E., Sangai, T., Wu, S., Hsiao, A., Ruiz-Esparza, G. U., Gonzalez-Delgado, C. A., et al. (2014). Colocalized Delivery of Rapamycin and Paclitaxel to Tumors Enhances Synergistic Targeting of the PI3K/Akt/mTOR Pathway. Mol. Ther. 22, 1310-1319. doi:10.1038/mt.2014.27

Blaumueller, C. M., Qi, H., Zagouras, P., and Artavanis-Tsakonas, S. (1997). Intracellular Cleavage of Notch Leads to a Heterodimeric Receptor on the Plasma Membrane. Cell 90, 281-291. doi:10.1016/s0092-8674(00)80336-0

Bonnefoi, H., Grellety, T., Tredan, O., Saghatchian, M., Dalenc, F., Mailliez, A., et al. (2016). A Phase II Trial of Abiraterone Acetate Plus Prednisone in Patients with Triple-Negative Androgen Receptor Positive Locally Advanced or Metastatic Breast Cancer (UCBG 12-1). Ann. Oncol. 27, 812-818. doi:10. 1093/annonc/mdw067

Brandes, L. J., Arron, R. J., Bogdanovic, R. P., Tong, J., Zaborniak, C. L., Hogg, G. R., et al. (1992). Stimulation of Malignant Growth in Rodents by Antidepressant Drugs at Clinically Relevant Doses. Cancer Res. 52, 3796-3800.

Carey, L. A., Rugo, H. S., Marcom, P. K., Mayer, E. L., Esteva, F. J., Ma, C. X., et al. (2012). TBCRC 001: Randomized Phase II Study of Cetuximab in Combination with Carboplatin in Stage IV Triple-Negative Breast Cancer. Jco 30, 2615-2623. doi:10.1200/jco.2010.34.5579

Casey, S. C., Vaccari, M., Al-Mulla, F., Al-Temaimi, R., Amedei, A., Barcellos-Hoff, M. H., et al. (2015). The Effect of Environmental Chemicals on the Tumor Microenvironment. Carcin 36, S160-S183. doi:10.1093/carcin/bgv035

Castelló, A., Pollán, M., Buijsse, B., Ruiz, A., Casas, A. M., Baena-Cañada, J. M., et al. (2014). Spanish Mediterranean Diet and Other Dietary Patterns and Breast Cancer Risk: Case-Control EpiGEICAM Study. Br. J. Cancer 111, 1454-1462. doi:10.1038/bjc.2014.434

Chan, S. M., Weng, A. P., Tibshirani, R., Aster, J. C., and Utz, P. J. (2007). Notch Signals Positively Regulate Activity of the mTOR Pathway in T-Cell Acute Lymphoblastic Leukemia. Blood J. Am. Soc. Hematol. 110, 278-286. doi:10. 1182/blood-2006-08-039883

Chang, J.-W., DIng, Y., Tahir Ul Qamar, M., Shen, Y., Gao, J., and Chen, L.-L. (2019). A Deep Learning Model Based on Sparse Auto-Encoder for Prioritizing Cancer-Related Genes and Drug Target Combinations. Carcinogenesis 40, 624-632. doi:10.1093/carcin/bgz044

Checka, C. M., Chun, J. E., Schnabel, F. R., Lee, J., and Toth, H. (2012). The Relationship of Mammographic Density and Age: Implications for Breast Cancer Screening. Am. J. Roentgenology 198, W292-W295. doi:10.2214/ajr. 10.6049

Coogan, P. F., Rao, S. R., Rosenberg, L., Palmer, J. R., Strom, B. L., Zauber, A. G., et al. (1999). The Relationship of Nonsteroidal Anti-inflammatory Drug Use to the Risk of Breast Cancer. Prev. Med. 29, 72-76. doi:10.1006/pmed.1999.0518

Cooney, C. A., Jousheghany, F., Yao-Borengasser, A., Phanavanh, B., Gomes, T., Kieber-Emmons, A. M., et al. (2011). Chondroitin Sulfates Play a Major Role in Breast Cancer Metastasis: a Role for CSPG4 and CHST11 Gene Expression in Forming Surface P-Selectin Ligands in Aggressive Breast Cancer Cells. Breast Cancer Res. 13, R58-R15. doi:10.1186/bcr2895

Corda, G., Sala, G., Lattanzio, R., Iezzi, M., Sallese, M., Fragassi, G., et al. (2017). Functional and Prognostic Significance of the Genomic Amplification of 
Frizzled 6 (FZD6) in Breast Cancer. J. Pathol. 241, 350-361. doi:10.1002/path. 4841

Coronado, G. D., Beasley, J., and Livaudais, J. (2011). Alcohol Consumption and the Risk of Breast Cancer. Salud Publica Mex 53, 440-447. doi:10.1111/acer. 13071

Corso, G., Veronesi, P., Sacchini, V., and Galimberti, V. (2018). Prognosis and Outcome in CDH1-Mutant Lobular Breast Cancer. Eur. J. Cancer Prev. 27 (3). 237-238. doi:10.1097/CEJ.0000000000000405

Cotterchio, M., Kreiger, N., Darlington, G., and Steingart, A. (2000). Antidepressant Medication Use and Breast Cancer Risk. Am. J. Epidemiol. 151, 951-957. doi:10.1093/oxfordjournals.aje.a010138

Couch, F. J., Cerhan, J. R., Vierkant, R. A., Grabrick, D. M., Therneau, T. M., Pankratz, V. S., et al. (2001). Cigarette Smoking Increases Risk for Breast Cancer in High-Risk Breast Cancer Families. Cancer Epidemiol. Biomarkers Prev. 10, 327-332.

Cui, Y., and Rohan, T. E. (2006). Vitamin D, Calcium, and Breast Cancer Risk: a Review. Cancer Epidemiol. Biomarkers Prev. 15, 1427-1437. doi:10.1158/10559965.epi-06-0075

Cuzick, J. (2003). Epidemiology of Breast Cancer - Selected Highlights. The Breast 12, 405-411. doi:10.1016/s0960-9776(03)00144-9

Dandamudi, A., Tommie, J., Nommsen-Rivers, L., and Couch, S. (2018). Dietary Patterns and Breast Cancer Risk: a Systematic Review. Anticancer Res. 38, 3209-3222. doi:10.21873/anticanres.12586

De Vos, M., Schreiber, V., and Dantzer, F. (2012). The Diverse Roles and Clinical Relevance of PARPs in DNA Damage Repair: Current State of the Art. Biochem. Pharmacol. 84, 137-146. doi:10.1016/j.bcp.2012.03.018

Dean, M., Fojo, T., and Bates, S. (2005). Tumour Stem Cells and Drug Resistance. Nat. Rev. Cancer 5, 275-284. doi:10.1038/nrc1590

Deepak, K. G. K., Vempati, R., Nagaraju, G. P., Dasari, V. R., S., N., Rao, D. N., et al. (2020). Tumor Microenvironment: Challenges and Opportunities in Targeting Metastasis of Triple Negative Breast Cancer. Pharmacol. Res. 153, 104683. doi:10.1016/j.phrs.2020.104683

Denoyelle, C., Vasse, M., Körner, M., Mishal, Z., Ganné, F., Vannier, J.-P., et al. (2001). Cerivastatin, an Inhibitor of HMG-CoA Reductase, Inhibits the Signaling Pathways Involved in the Invasiveness and Metastatic Properties of Highly Invasive Breast Cancer Cell Lines: an In Vitro Study. Carcinogenesis 22, 1139-1148. doi:10.1093/carcin/22.8.1139

Dent, R., Trudeau, M., Pritchard, K. I., Hanna, W. M., Kahn, H. K., Sawka, C. A., et al. (2007). Triple-negative Breast Cancer: Clinical Features and Patterns of Recurrence. Clin. Cancer Res. 13, 4429-4434. doi:10.1158/1078-0432.ccr-063045

DeSantis, C. E., Fedewa, S. A., Goding Sauer, A., Kramer, J. L., Smith, R. A., and Jemal, A. (2016). Breast Cancer Statistics, 2015: Convergence of Incidence Rates between Black and white Women. Ca: A. Cancer J. Clinicianscancer J. Clin. 66, 31-42. doi: $10.3322 /$ caac. 21320

Donepudi, M. S., Kondapalli, K., Amos, S. J., and Venkanteshan, P. (2014). Breast Cancer Statistics and Markers. J. Cancer Res. Ther. 10, 506-511. doi:10.4103/ 0973-1482.137927

Dudley, J. C., Lin, M.-T., Le, D. T., and Eshleman, J. R. (2016). Microsatellite Instability as a Biomarker for PD-1 Blockade. Clin. Cancer Res. 22, 813-820. doi:10.1158/1078-0432.ccr-15-1678

Dujon, A. M., Capp, J.-P., Brown, J. S., Pujol, P., Gatenby, R. A., Ujvari, B., et al. (2021). Is There One Key Step in the Metastatic Cascade. Cancers 13, 3693. doi:10.3390/cancers13153693

Dunneram, Y., Greenwood, D. C., and Cade, J. E. (2019). Diet and Risk of Breast, Endometrial and Ovarian Cancer: UK Women's Cohort Study. Br. J. Nutr. 122, 564-574. doi:10.1017/s0007114518003665

Dyrstad, S. W., Yan, Y., Fowler, A. M., and Colditz, G. A. (2015). Breast Cancer Risk Associated with Benign Breast Disease: Systematic Review and Meta-Analysis. Breast Cancer Res. Treat. 149, 569-575. doi:10.1007/s10549-014-3254-6

Eccles, S. A. (2011). The Epidermal Growth Factor receptor/Erb-B/HER Family in normal and Malignant Breast Biology. Int. J. Dev. Biol. 55, 685-696. doi:10. 1387/ijdb.113396se

Ellisen, L. W. (2011). PARP Inhibitors in Cancer Therapy: Promise, Progress, and Puzzles. Cancer Cell 19, 165-167. doi:10.1016/j.ccr.2011.01.047

Fatima, Z., Guo, P., Huang, D., Lu, Q., Wu, Q., Dai, M., et al. (2018). The Critical Role of p16/Rb Pathway in the Inhibition of GH3 Cell Cycle Induced by T-2 Toxin. Toxicology 400-401, 28-39. doi:10.1016/j.tox.2018.03.006
Feng, B., Xu, Z., Zhou, F., Yu, H., Sun, Q., Wang, D., et al. (2015). Near Infrared Light-Actuated Gold Nanorods with Cisplatin-Polypeptide Wrapping for Targeted Therapy of Triple Negative Breast Cancer. Nanoscale 7, 14854-14864. doi:10.1039/c5nr03693c

Fiolet, T., Srour, B., Sellem, L., Kesse-Guyot, E., Allès, B., Méjean, C., et al. (2018). Consumption of Ultra-processed Foods and Cancer Risk: Results from NutriNet-Santé Prospective Cohort. BMJ 360, bmj k322. doi:10.1136/bmj.k322

Foulkes, W. D., Smith, I. E., and Reis-Filho, J. S. (2010). Triple-negative Breast Cancer. N. Engl. J. Med. 363, 1938-1948. doi:10.1056/nejmra1001389

Friedman, G. D., Oestreicher, N., Chan, J., Quesenberry, C. P., Udaltsova, N., and Habel, L. A. (2006). Antibiotics and Risk of Breast Cancer: up to 9 Years of Follow-Up of 2.1 Million Women. Cancer Epidemiol. Biomarkers Prev. 15, 2102-2106. doi:10.1158/1055-9965.epi-06-0401

Fruman, D. A., and Rommel, C. (2014). PI3K and Cancer: Lessons, Challenges and Opportunities. Nat. Rev. Drug Discov. 13, 140-156. doi:10.1038/nrd4204

Fudala, R., Raut, S., Maliwal, B. P., Zerda, T. W., Gryczynski, I., Simanek, E., et al. (2013). FRET Enhanced Fluorescent Nanodiamonds. Curr. Pharm. Biotechnol. 14, 1127-1133. doi:10.2174/138920101413140605110711

Ghoncheh, M., Pournamdar, Z., and Salehiniya, H. (2016). Incidence and Mortality and Epidemiology of Breast Cancer in the World. Asian Pac. J. Cancer Prev. 17, 43-46. doi:10.7314/apjcp.2016.17.s3.43

Giancotti, F. G. (2013). Mechanisms Governing Metastatic Dormancy and Reactivation. Cell 155, 750-764. doi:10.1016/j.cell.2013.10.029

Gianni, L., Huang, C. S., Egle, D., Bermejo, B., Zamagni, C., Thill, M., et al. (2019). Pathologic Complete Response (pCR) to Neoadjuvant Treatment with or without Atezolizumab in Triple Negative, Early High-Risk and Locally Advanced Breast Cancer NeoTRIPaPDL1 Michelangelo Randomized Study. San Antonio Breast Cancer Symp. 80 (9), GS3-04. doi:10.1158/1538-7445. SABCS19-GS3-04

Gilewski, T., Ragupathi, G., Bhuta, S., Williams, L. J., Musselli, C., Zhang, X.-F., et al. (2001). Immunization of Metastatic Breast Cancer Patients with a Fully Synthetic Globo H Conjugate: a Phase I Trial. Proc. Natl. Acad. Sci. 98, 3270-3275. doi:10.1073/pnas.051626298

Giordano, S. H. (2018). Breast Cancer in Men. N. Engl. J. Med. 378, 2311-2320. doi:10.1056/nejmra1707939

Gu, Y., Masiero, M., and Banham, A. H. (2016). Notch Signaling: its Roles and Therapeutic Potential in Hematological Malignancies. Oncotarget 7, 29804-29823. doi:10.18632/oncotarget.7772

Gucalp, A., Danso, M. A., Elias, A. D., Bardia, A., Ali, H. Y., Potter, D., et al. (2017). Phase (Ph) 2 Stage 1 Clinical Activity of Seviteronel, a Selective CYP17-Lyase and Androgen Receptor (AR) Inhibitor, in Women with Advanced AR+ TripleNegative Breast Cancer (TNBC) or Estrogen Receptor (ER)+ BC: CLARITY-01. Journal of Clinical Oncology. 35 (15_Suppl. 1). 1102. 10.1200/JCO.2017.35.15_ suppl.1102

Gucalp, A., Tolaney, S., Isakoff, S. J., Ingle, J. N., Liu, M. C., Carey, L. A., et al. (2013). Phase II Trial of Bicalutamide in Patients with Androgen ReceptorPositive, Estrogen Receptor-Negative Metastatic Breast Cancer. Clin. Cancer Res. 19, 5505-5512. doi:10.1158/1078-0432.ccr-12-3327

Gurney, A., Axelrod, F., Bond, C. J., Cain, J., Chartier, C., Donigan, L., et al. (2012). Wnt Pathway Inhibition via the Targeting of Frizzled Receptors Results in Decreased Growth and Tumorigenicity of Human Tumors. Proc. Natl. Acad. Sci. 109, 11717-11722. doi:10.1073/pnas.1120068109

Hayashi, K., Nakamura, M., Sakamoto, W., Yogo, T., Miki, H., Ozaki, S., et al. (2013). Superparamagnetic Nanoparticle Clusters for Cancer Theranostics Combining Magnetic Resonance Imaging and Hyperthermia Treatment. Theranostics 3, 366-376. doi:10.7150/thno. 5860

Helleday, T. (2011). The Underlying Mechanism for the PARP and BRCA Synthetic Lethality: Clearing up the Misunderstandings. Mol. Oncol. 5, 387-393. doi:10.1016/j.molonc.2011.07.001

Hilakivi-Clarke, L. (2014). Maternal Exposure to Diethylstilbestrol during Pregnancy and Increased Breast Cancer Risk in Daughters. Breast Cancer Res. 16, 208-210. doi:10.1186/bcr3649

Hill, D. A., Prossnitz, E. R., Royce, M., and Nibbe, A. (2019). Temporal Trends in Breast Cancer Survival by Race and Ethnicity: A Population-Based Cohort Study. PLoS One 14, e0224064. doi:10.1371/journal.pone.0224064

Hoffman-Goetz, L., Apter, D., Demark-Wahnefried, W., Goran, M. I., McTiernan, A., and Reichman, M. E. (1998). Possible Mechanisms Mediating an Association between Physical Activity and Breast Cancer. Cancer 83, 
621-628. doi:10.1002/(sici)1097-0142(19980801)83:3+<621:aid-cncr4>3.0.co; $2-\mathrm{a}$

Hoover, R. N., Hyer, M., Pfeiffer, R. M., Adam, E., Bond, B., Cheville, A. L., et al. (2011). Adverse Health Outcomes in Women Exposed In Utero to Diethylstilbestrol. N. Engl. J. Med. 365, 1304-1314. doi:10.1056/nejmoa1013961

Hormones, E., Key, T. J., Reeves, P. N. G. K., Travis, R. C., Alberg, A. J., Barricarte, A., et al. (2013). Sex Hormones and Risk of Breast Cancer in Premenopausal Women: a Collaborative Reanalysis of Individual Participant Data from Seven Prospective Studies. Lancet Oncol. 14, 1009-1019. doi:10.1016/S1470-2045(13) 70301-2

Howard, F. M., and Olopade, O. I. (2021). Epidemiology of Triple-Negative Breast Cancer. Cancer J. 27, 8-16. doi:10.1097/ppo.0000000000000500

Hsiao, Y.-C., Yeh, M.-H., Chen, Y.-J., Liu, J.-F., Tang, C.-H., and Huang, W.-C. (2015). Lapatinib Increases Motility of Triple-Negative Breast Cancer Cells by Decreasing miRNA-7 and Inducing Raf-1/mapk-dependent Interleukin-6. Oncotarget 6, 37965-37978. doi:10.18632/oncotarget.5700

Hudis, C. A., and Gianni, L. (2011). Triple-negative Breast Cancer: an Unmet Medical Need. Oncologist 16, 1-11. doi:10.1634/theoncologist.2011-s1-01

Incorvaia, L., Fanale, D., Bono, M., Calò, V., Fiorino, A., Brando, C., et al. (2020). BRCA1/2 Pathogenic Variants in Triple-Negative versus Luminal-like Breast Cancers: Genotype-Phenotype Correlation in a Cohort of 531 Patients. Ther. Adv. Med. Oncol. 12, 1758835920975326. doi:10.1177/1758835920975326

Iyengar, N. M., Arthur, R., Manson, J. E., Chlebowski, R. T., Kroenke, C. H., Peterson, L., et al. (2019). Association of Body Fat and Risk of Breast Cancer in Postmenopausal Women with Normal Body Mass Index. JAMA Oncol. 5, 155-163. doi:10.1001/jamaoncol.2018.5327

Jamdade, V. S., Sethi, N., Mundhe, N. A., Kumar, P., Lahkar, M., and Sinha, N. (2015). Therapeutic Targets of Triple-Negative Breast Cancer: a Review. $\mathrm{Br}$. J. Pharmacol. 172, 4228-4237. doi:10.1111/bph.13211

James, F. R., Wootton, S., Jackson, A., Wiseman, M., Copson, E. R., and Cutress, R. I. (2015). Obesity in Breast Cancer - what Is the Risk Factor. Eur. J. Cancer 51, 705-720. doi:10.1016/j.ejca.2015.01.057

Johns, L. E., Jones, M. E., Schoemaker, M. J., McFadden, E., Ashworth, A., and Swerdlow, A. J. (2018). Domestic Light at Night and Breast Cancer Risk: a Prospective Analysis of 105000 UK Women in the Generations Study. Br. J. Cancer 118, 600-606. doi:10.1038/bjc.2017.359

Kaplan, H. G., and Malmgren, J. A. (2008). Impact of Triple Negative Phenotype on Breast Cancer Prognosis. Breast J. 14, 456-463. doi:10.1111/j.1524-4741.2008. 00622.x

Khan, W., Ashfaq, U. A., Aslam, S., Saif, S., Aslam, T., Tusleem, K., et al. (2017). Anticancer Screening of Medicinal Plant Phytochemicals against Cyclindependent Kinase-2 (CDK2): An In-Silico Approach. Adv. Life Sci. 4, 113-119.

Kim, E. Y., Chang, Y., Ahn, J., Yun, J. S., Park, Y. L., Park, C. H., et al. (2020). Mammographic Breast Density, its Changes, and Breast Cancer Risk in Premenopausal and Postmenopausal Women. Cancer 126, 4687-4696. doi:10.1002/cncr.33138

Kluźniak, W., Wokołorczyk, D., Rusak, B., Huzarski, T., Gronwald, J., Stempa, K., et al. (2019). Inherited Variants in XRCC2 and the Risk of Breast Cancer. Breast Cancer Res. Treat. 178, 657-663. doi:10.1007/s10549-019-05415-5

Kohler, B. A., Sherman, R. L., Howlader, N., Jemal, A., Ryerson, A. B., Henry, K. A., et al. (2015). Annual Report to the Nation on the Status of Cancer, 1975-2011, Featuring Incidence of Breast Cancer Subtypes by Race/ethnicity, Poverty, and State. J. Natl. Cancer Inst. 107, djv048. doi:10.1093/jnci/djv048

Kolb, R., and Zhang, W. (2020). Obesity and Breast Cancer: A Case of Inflamed Adipose Tissue. Cancers 12, 1686. doi:10.3390/cancers12061686

Kuroda, H., Jamiyan, T., Yamaguchi, R., Kakumoto, A., Abe, A., Harada, O., et al. (2021). Tumor Microenvironment in Triple-Negative Breast Cancer: the Correlation of Tumor-Associated Macrophages and Tumor-Infiltrating Lymphocytes. Clin. Transl. Oncol. 23, 2513-2525. doi:10.1007/s12094-02102652-3

Kyu, H. H., Bachman, V. F., Alexander, L. T., Mumford, J. E., Afshin, A., Estep, K., et al. (2016). Physical Activity and Risk of Breast Cancer, colon Cancer, Diabetes, Ischemic Heart Disease, and Ischemic Stroke Events: Systematic Review and Dose-Response Meta-Analysis for the Global Burden of Disease Study 2013. bmj 354, i3857. doi:10.1136/bmj.i3857

Lehmann, B. D., Jovanović, B., Chen, X., Estrada, M. V., Johnson, K. N., Shyr, Y., et al. (2016). Refinement of Triple-Negative Breast Cancer Molecular Subtypes:
Implications for Neoadjuvant Chemotherapy Selection. PLoS One 11, e0157368. doi:10.1371/journal.pone.0157368

Leso, V., Ercolano, M. L., Cioffi, D. L., and Iavicoli, I. (2019). Occupational Chemical Exposure and Breast Cancer Risk According to Hormone Receptor Status: A Systematic Review. Cancers 11, 1882. doi:10.3390/ cancers 11121882

Li, M.-J., Yin, Y.-C., Wang, J., and Jiang, Y.-F. (2014). Green tea Compounds in Breast Cancer Prevention and Treatment. Wjco 5, 520. doi:10.5306/wjco.v5. i3.520

Li, Y., Maitah, M. i. Y., Ahmad, A., Kong, D., Bao, B., and Sarkar, F. H. (2012). Targeting the Hedgehog Signaling Pathway for Cancer Therapy. Expert Opin. Ther. Targets 16, 49-66. doi:10.1517/14728222.2011.617367

Liang, R., Liu, L., He, H., Chen, Z., Han, Z., Luo, Z., et al. (2018). Oxygen-boosted Immunogenic Photodynamic Therapy with Gold Nanocages@manganese Dioxide to Inhibit Tumor Growth and Metastases. Biomaterials 177, 149-160. doi:10.1016/j.biomaterials.2018.05.051

Liao, W.-S., Ho, Y., Lin, Y.-W., Naveen Raj, E., Liu, K.-K., Chen, C., et al. (2019). Targeting EGFR of Triple-Negative Breast Cancer Enhances the Therapeutic Efficacy of Paclitaxel- and Cetuximab-Conjugated Nanodiamond Nanocomposite. Acta Biomater. 86, 395-405. doi:10.1016/j.actbio.2019.01.025 Liu, D., and Chen, Z. (2013). The Effect of Curcumin on Breast Cancer Cells. J. Breast Cancer 16, 133-137. doi:10.4048/jbc.2013.16.2.133

Liu, Y., Nguyen, N., and Colditz, G. A. (2015). Links between Alcohol Consumption and Breast Cancer: a Look at the Evidence. Womens Health (Lond Engl. 11, 65-77. doi:10.2217/whe.14.62

Łukasiewicz, S., Czeczelewski, M., Forma, A., Baj, J., Sitarz, R., and Stanisławek, A. (2021). Breast Cancer-Epidemiology, Risk Factors, Classification, Prognostic Markers, and Current Treatment Strategies-An Updated Review. Cancers (Basel) 13, 4287. doi:10.3390/cancers13174287

Mahfoudh, W., Bettaieb, I., Ghedira, R., Snoussi, K., Bouzid, N., Klayech, Z., et al. (2019). Contribution of BRCA1 5382insC Mutation in Triple Negative Breast Cancer in Tunisia. J. Transl. Med. 17, 123-125. doi:10. 1186/s12967-019-1873-8

Martin, M., Ruiz, A., Borrego, M. R., Barnadas, A., González, S., Calvo, L., et al. (2013). Fluorouracil, Doxorubicin, and Cyclophosphamide (FAC) versus FAC Followed by Weekly Paclitaxel as Adjuvant Therapy for High-Risk, NodeNegative Breast Cancer: Results from the GEICAM/2003-02 Study. J. Clin. Oncol. 31, 2593-2599. doi:10.1200/JCO.2012.46.9841

McGuire, A., Brown, J., Malone, C., McLaughlin, R., and Kerin, M. (2015). Effects of Age on the Detection and Management of Breast Cancer. Cancers 7, 908-929. doi:10.3390/cancers7020815

Medina, M. A., Oza, G., Sharma, A., Arriaga, L. G., Hernández Hernández, J. M., Rotello, V. M., et al. (2020). Triple-negative Breast Cancer: a Review of Conventional and Advanced Therapeutic Strategies. Ijerph 17, 2078. doi:10. 3390/ijerph17062078

Mehta, A. K., Cheney, E. M., Hartl, C. A., Pantelidou, C., Oliwa, M., Castrillon, J. A., et al. (2021). Targeting Immunosuppressive Macrophages Overcomes PARP Inhibitor Resistance in BRCA1-Associated Triple-Negative Breast Cancer. Nat. Cancer 2, 66-82. doi:10.1038/s43018-020-00148-7

Meng, Q., Meng, J., Ran, W., Wang, J., Zhai, Y., Zhang, P., et al. (2018). LightActivated Core-Shell Nanoparticles for Spatiotemporally Specific Treatment of Metastatic Triple-Negative Breast Cancer. ACS Nano 12, 2789-2802. doi:10. 1021/acsnano.7b09210

Mersin, H., Yildirim, E., Berberoglu, U., and Gülben, K. (2008). The Prognostic Importance of Triple Negative Breast Carcinoma. The Breast 17, 341-346. doi:10.1016/j.breast.2007.11.031

Michalet, X., Pinaud, F. F., Bentolila, L. A., Tsay, J. M., Doose, S., Li, J. J., et al. (2005). Quantum Dots for Live Cells, In Vivo Imaging, and Diagnostics. Science 307, 538-544. doi:10.1126/science.1104274

Muneer, I., Ahmad, S., Naz, A., Abbasi, S. W., Alblihy, A., Aloliqi, A. A., et al. (2021). Discovery of Novel Inhibitors from Medicinal Plants for V-Domain Ig Suppressor of T-Cell Activation (VISTA). Front. Mol. Biosci., 8. 716735. doi:10. 3389/fmolb.2021.716735

Muneer, I., Ul Qamar, M. T., Tusleem, K., Abdul Rauf, S., Hussain, H. M. J., and Siddiqi, A. R. (2019). Discovery of Selective Inhibitors for Cyclic AMP Response Element-Binding Protein. Anticancer. Drugs 30, 363-373. doi:10.1097/CAD. 0000000000000727 
Murai, J., Huang, S.-y. N., Das, B. B., Renaud, A., Zhang, Y., Doroshow, J. H., et al. (2012). Trapping of PARP1 and PARP2 by Clinical PARP Inhibitors. Cancer Res. 72, 5588-5599. doi:10.1158/0008-5472.can-12-2753

Nabholtz, J. M., Abrial, C., Mouret-Reynier, M. A., Dauplat, M. M., Weber, B., Gligorov, J., et al. (2014). Multicentric Neoadjuvant Phase II Study of Panitumumab Combined with an Anthracycline/taxane-Based Chemotherapy in Operable Triple-Negative Breast Cancer: Identification of Biologically Defined Signatures Predicting Treatment Impact. Ann. Oncol. 25, 1570-1577. doi:10.1093/annonc/mdu183

Nanda, R., Liu, M. C., Yau, C., Shatsky, R., Pusztai, L., Wallace, A., et al. (2020). Effect of Pembrolizumab Plus Neoadjuvant Chemotherapy on Pathologic Complete Response in Women with Early-Stage Breast Cancer. JAMA Oncol. 6, 676-684. doi:10.1001/jamaoncol.2019.6650

Narod, S. A. (2011). Hormone Replacement Therapy and the Risk of Breast Cancer. Nat. Rev. Clin. Oncol. 8, 669-676. doi:10.1038/nrclinonc.2011.110

Ng, J., and Shuryak, I. (2015). Minimizing Second Cancer Risk Following Radiotherapy: Current Perspectives. Cancer Manag. Res. 7, 1-11. doi:10. 2147/CMAR.S47220

Nguyen, D. X., and Massagué, J. (2007). Genetic Determinants of Cancer Metastasis. Nat. Rev. Genet. 8, 341-352. doi:10.1038/nrg2101

Nie, L., Wei, Y., Zhang, F., Hsu, Y. H., Chan, L. C., Xia, W., et al. (2019). CDK2mediated Site-specific Phosphorylation of EZH2 Drives and Maintains TripleNegative Breast Cancer. Nat. Commun. 10, 5114-5115. doi:10.1038/s41467019-13105-5

Nofech-Mozes, S., Trudeau, M., Kahn, H. K., Dent, R., Rawlinson, E., Sun, P., et al. (2009). Patterns of Recurrence in the Basal and Non-basal Subtypes of TripleNegative Breast Cancers. Breast Cancer Res. Treat. 118, 131-137. doi:10.1007/ s10549-008-0295-8

Ohta, A. (2016). A Metabolic Immune Checkpoint: Adenosine in Tumor Microenvironment. Front. Immunol. 7, 109. doi:10.3389/fimmu.2016.00109

Palmer, J. R., Wise, L. A., Hatch, E. E., Troisi, R., Titus-Ernstoff, L., Strohsnitter, W., et al. (2006). Prenatal Diethylstilbestrol Exposure and Risk of Breast Cancer. Cancer Epidemiol. Biomarkers Prev. 15, 1509-1514. doi:10.1158/1055-9965.epi06-0109

Palomero, T., Barnes, K. C., Real, P. J., Glade Bender, J. L., Sulis, M. L., Murty, V. V., et al. (2006). CUTLL1, a Novel Human T-Cell Lymphoma Cell Line with T(7;9) Rearrangement, Aberrant NOTCH1 Activation and High Sensitivity to $\gamma$ secretase Inhibitors. Leukemia 20, 1279-1287. doi:10.1038/sj.leu.2404258

Pardoll, D. M. (2012). The Blockade of Immune Checkpoints in Cancer Immunotherapy. Nat. Rev. Cancer 12, 252-264. doi:10.1038/nrc3239

Parikh, R. R., Housman, D., Yang, Q., Toppmeyer, D., Wilson, L. D., and Haffty, B. G. (2008). Prognostic Value of Triple-Negative Phenotype at the Time of Locally Recurrent, Conservatively Treated Breast Cancer. Int. J. Radiat. Oncol. Biol. Phys. 72, 1056-1063. doi:10.1016/j.ijrobp.2008. 02.066

Park, S. R., and Chen, A. (2012). Poly(Adenosine Diphosphate-Ribose) Polymerase Inhibitors in Cancer Treatment. Hematology/oncology Clin. North. America Clin. 26, 649-670. doi:10.1016/j.hoc.2012.02.012

Powderly, J. D., de Souza, P. L., Gutierrez, R., Horvath, L., Seitz, L., Ashok, D., et al. (2019). AB928, a Novel Dual Adenosine Receptor Antagonist, Combined with Chemotherapy or AB122 (Anti-PD-1) in Patients (Pts) with Advanced Tumors: Preliminary Results from Ongoing Phase I Studies. Journal of Clinical Oncology. 30 (5). 493. doi:10.1093/annonc/mdz253.032

Protani, M., Coory, M., and Martin, J. H. (2010). Effect of Obesity on Survival of Women with Breast Cancer: Systematic Review and Meta-Analysis. Breast Cancer Res. Treat. 123, 627-635. doi:10.1007/s10549-010-0990-0

Rachdaoui, N., and Sarkar, D. K. (2013). Effects of Alcohol on the Endocrine System. Endocrinol. Metab. Clin. North. America 42, 593-615. doi:10.1016/j.ecl. 2013.05.008

Reis-Filho, J. S., and Tutt, A. N. (2008). Triple Negative Tumours: a Critical Review. Histopathology 52, 108-118. doi:10.1111/j.1365-2559.2007.02889.x

Reynolds, S. (2007). Triple-negative Breast Cancer Disproportionately Affects African American and Hispanic Women. Cancer Bull. 4. doi:10.1037/ e458842008-005

Rhee, J., Han, S. W., Oh, D. Y., Kim, J. H., Im, S. A., Han, W., et al. (2008). The Clinicopathologic Characteristics and Prognostic Significance of TripleNegativity in Node-Negative Breast Cancer. BMC Cancer 8, 307-308. doi:10.1186/1471-2407-8-307
Riaz, M., Ashfaq, U. A., Qasim, M., Yasmeen, E., Ul Qamar, M. T., and Anwar, F. (2017). Screening of Medicinal Plant Phytochemicals as Natural Antagonists of P53-MDM2 Interaction to Reactivate P53 Functioning. Anticancer. Drugs 28, 1032-1038. doi:10.1097/CAD.0000000000000548

Roma-Rodrigues, C., Mendes, R., Baptista, P., and Fernandes, A. (2019). Targeting Tumor Microenvironment for Cancer Therapy. Ijms 20, 840. doi:10.3390/ ijms 20040840

Schacht, D. V., Yamaguchi, K., Lai, J., Kulkarni, K., Sennett, C. A., and Abe, H. (2014). Importance of a Personal History of Breast Cancer as a Risk Factor for the Development of Subsequent Breast Cancer: Results from Screening Breast MRI. Am. J. Roentgenology 202, 289-292. doi:10.2214/ajr.13.11553

Schmid, P., Adams, S., Rugo, H. S., Schneeweiss, A., Barrios, C. H., Iwata, H., et al. (2018). Atezolizumab and Nab-Paclitaxel in Advanced Triple-Negative Breast Cancer. N. Engl. J. Med. 379, 2108-2121. doi:10.1056/nejmoa1809615

Shahbandi, A., Nguyen, H. D., and Jackson, J. G. (2020). TP53 Mutations and Outcomes in Breast Cancer: reading beyond the Headlines. Trends Cancer 6, 98-110. doi:10.1016/j.trecan.2020.01.007

Sharma, A., Paranjape, A. N., Rangarajan, A., and Dighe, R. R. (2012). A Monoclonal Antibody against Human Notch1 Ligand-Binding Domain Depletes Subpopulation of Putative Breast Cancer Stem-like Cells. Mol. Cancer Ther. 11, 77-86. doi:10.1158/1535-7163.mct-11-0508

Shiovitz, S., and Korde, L. A. (2015). Genetics of Breast Cancer: a Topic in Evolution. Ann. Oncol. 26, 1291-1299. doi:10.1093/annonc/mdv022

Sikov, W. M., Berry, D. A., Perou, C. M., Singh, B., Cirrincione, C. T., Tolaney, S. M., et al. (2015). Impact of the Addition of Carboplatin And/or Bevacizumab to Neoadjuvant Once-Per-Week Paclitaxel Followed by Dose-Dense Doxorubicin and Cyclophosphamide on Pathologic Complete Response Rates in Stage II to III Triple-Negative Breast Cancer: CALGB 40603 (Alliance). Jco 33, 13-21. doi:10.1200/jco.2014.57.0572

Singh, S., Numan, A., Agrawal, N., Tambuwala, M. M., Singh, V., and Kesharwani, P. (2020). Role of Immune Checkpoint Inhibitors in the Revolutionization of Advanced Melanoma Care. Int. Immunopharmacology 83, 106417. doi:10.1016/ j.intimp.2020.106417

Singh, S., Numan, A., Maddiboyina, B., Arora, S., Riadi, Y., Md, S., et al. (2021). The Emerging Role of Immune Checkpoint Inhibitors in the Treatment of TripleNegative Breast Cancer. Drug Discov. Today 26 (7), 1721-1727. doi:10.1016/j. drudis.2021.03.011

Sobande, F., Dušek, L., Matějková, A., Rozkoš, T., Laco, J., and Ryška, A. (2015). EGFR in Triple Negative Breast Carcinoma: Significance of Protein Expression and High Gene Copy Number. Cesk Patol 51, 80-86.

Socolov, D., Anghelache, I., Ilea, C., Socolov, R., and Carauleanu, A. (2015). Benign Breast Disease and the Risk of Breast Cancer in the Next 15 Years. Rev. Med. Chir. Soc. Med. Nat. Iasi 119, 135-140.

Speiser, J. J., Erşahin, Ç., and Osipo, C. (2013). The Functional Role of Notch Signaling in Triple-Negative Breast Cancer. Vitam. II \& Horm. 93, 277-306. doi:10.1016/b978-0-12-416673-8.00013-7

Stanton, S. E., Adams, S., and Disis, M. L. (2016). Variation in the Incidence and Magnitude of Tumor-Infiltrating Lymphocytes in Breast Cancer Subtypes. JAMA Oncol. 2, 1354-1360. doi:10.1001/jamaoncol.2016.1061

Suleman, M., Tahir Ul Qamar, M., Saleem, S., Ahmad, S., Ali, S. S., Khan, H., et al. (2021). Mutational Landscape of Pirin and Elucidation of the Impact of Most Detrimental Missense Variants that Accelerate the Breast Cancer Pathways: A Computational Modelling Study. Front. Mol. Biosci. 8, 692835. doi:10.3389/ fmolb.2021.692835

Swanner, J., Mims, J., Carroll, D. L., Akman, S. A., Furdui, C. M., Torti, S. V., et al. (2015). Differential Cytotoxic and Radiosensitizing Effects of Silver Nanoparticles on Triple-Negative Breast Cancer and Non-triple-negative Breast Cells. Int. J. Nanomedicine 10, 3937-3953. doi:10.2147/IJN.S80349

Terry, P. D., and Rohan, T. E. (2002). Cigarette Smoking and the Risk of Breast Cancer in Women: a Review of the Literature. Cancer Epidemiol. Biomarkers Prev. 11, 953-971. doi:10.1007/s10549-017-4290-9

The Endogenous Hormones and Breast Cancer Collaborative Group, E., and Group, B. C. C. (2002). Endogenous Sex Hormones and Breast Cancer in Postmenopausal Women: Reanalysis of Nine Prospective Studies. J. Natl. Cancer Inst. 94, 606-616. doi:10.1093/jnci/94.8.606

Titus-Ernstoff, L., Longnecker, M. P., Newcomb, P. A., Dain, B., Greenberg, E. R., Mittendorf, R., et al. (1998). Menstrual Factors in Relation to Breast Cancer Risk. Cancer Epidemiol. Biomarkers Prev. 7, 783-789. 
Traina, T. A., Miller, K., Yardley, D. A., Eakle, J., Schwartzberg, L. S., O'Shaughnessy, J., et al. (2018). Enzalutamide for the Treatment of Androgen Receptor-Expressing Triple-Negative Breast Cancer. Jco 36, 884-890. doi:10.1200/jco.2016.71.3495

Tsai, J., Bertoni, D., Hernandez-Boussard, T., Telli, M. L., and Wapnir, I. L. (2016). Lymph Node Ratio Analysis after Neoadjuvant Chemotherapy Is Prognostic in Hormone Receptor-Positive and Triple-Negative Breast Cancer. Ann. Surg. Oncol. 23, 3310-3316. doi:10.1245/s10434-016-5319-8

Velasco, G., Sánchez, C., and Guzmán, M. (2016). Anticancer Mechanisms of Cannabinoids. Curr. Oncol. 23, 23-32. doi:10.3747/co.23.3080

Videnros, C., Selander, J., Wiebert, P., Albin, M., Plato, N., Borgquist, S., et al. (2020). Investigating the Risk of Breast Cancer Among Women Exposed to Chemicals: a Nested Case-Control Study Using Improved Exposure Estimates. Int. Arch. Occup. Environ. Health 93, 261-269. doi:10.1007/s00420-01901479-4

Vyas, D., Lopez-Hisijos, N., Gandhi, S., El-Dakdouki, M., Basson, M. D., Walsh, M. F., et al. (2015). Doxorubicin-Hyaluronan Conjugated Super-paramagnetic Iron Oxide Nanoparticles (DOX-HA-SPION) Enhanced Cytoplasmic Uptake of Doxorubicin and Modulated Apoptosis, IL-6 Release and NFkappaB Activity in Human MDA-MB-231 Breast Cancer Cells. J. Nanosci. Nanotechnol. 15, 6413-6422. doi:10.1166/jnn.2015.10834

Wang, J., Costantino, J. P., Tan-Chiu, E., Wickerham, D. L., Paik, S., and Wolmark, N. (2004). Lower-category Benign Breast Disease and the Risk of Invasive Breast Cancer. JNCI J. Natl. Cancer Inst. 96, 616-620. doi:10. 1093/jnci/djhs 105

Wang, L., Guo, J., Chang, J.-W., Tahir ul Qamar, M., and Chen, L.-L. (2018). Inference of Transcriptional Regulation from Expression Data Using Model Integration. Cbio 13, 426-434. doi:10.2174/1574893612666171006162012

Wang, X., Hui, T.-L., Wang, M.-Q., Liu, H., Li, R.-Y., and Song, Z.-C. (2019). Body Mass index at Diagnosis as a Prognostic Factor for Early-Stage Invasive Breast Cancer after Surgical Resection. Oncol. Res. Treat. 42, 190-196. doi:10.1159/ 000496548

Wang, X., Osada, T., Wang, Y., Yu, L., Sakakura, K., Katayama, A., et al. (2010). CSPG4 Protein as a New Target for the Antibody-Based Immunotherapy of Triple-Negative Breast Cancer. J. Natl. Cancer Inst. 102, 1496-1512. doi:10. 1093/jnci/djq343

Weijzen, S., Rizzo, P., Braid, M., Vaishnav, R., Jonkheer, S. M., Zlobin, A., et al. (2002). Activation of Notch-1 Signaling Maintains the Neoplastic Phenotype in Human Ras-Transformed Cells. Nat. Med. 8, 979-986. doi:10.1038/nm754

Wolff, A. C., Hammond, M. E. H., Hicks, D. G., Dowsett, M., McShane, L. M., Allison, K. H., et al. (2014). Recommendations for Human Epidermal Growth Factor Receptor 2 Testing in Breast Cancer: American Society of Clinical Oncology/College of American Pathologists Clinical Practice Guideline Update. Arch. Pathol. Lab. Med. 138, 241-256. doi:10.5858/arpa.2013-0953-sa

Won, K.-A., and Spruck, C. (2020). Triple-negative Breast Cancer Therapy: Current and Future Perspectives. Int. J. Oncol. 57 (6). 1245-1261. doi:10. 3892/ijo.2020.513

Wright, L., Frye, J., Gorti, B., Timmermann, B., and Funk, J. (2013). Bioactivity of Turmeric-Derived Curcuminoids and Related Metabolites in Breast Cancer. Cpd 19, 6218-6225. doi:10.2174/1381612811319340013

Wu, H.-C., Do, C., Andrulis, I. L., John, E. M., Daly, M. B., Buys, S. S., et al. (2018). Breast Cancer Family History and Allele-specific DNA Methylation in the Legacy Girls Study. Epigenetics 13, 240-250. doi:10.1080/15592294.2018. 1435243

Xie, J., Wang, X., and Proud, C. G. (2016). mTOR Inhibitors in Cancer Therapy. F1000Res 5, 71. doi:10.12688/f1000research.9207.1

Yam, C., Mani, S. A., and Moulder, S. L. (2017). Targeting the Molecular Subtypes of Triple Negative Breast Cancer: Understanding the Diversity to Progress the Field. Oncologist 22, 1086-1093. doi:10.1634/theoncologist.2017-0095

Yang, N., Zhou, T.-C., Lei, X.-X., Wang, C., Yan, M., Wang, Z.-F., et al. (2016). Inhibition of Sonic Hedgehog Signaling Pathway by Thiazole Antibiotic Thiostrepton Attenuates the CD44+/CD24-stem-like Population and
Sphere-Forming Capacity in Triple-Negative Breast Cancer. Cell. Physiol. Biochem. 38, 1157-1170. doi:10.1159/000443066

Yang, X., Phillips, D. L., Ferguson, A. T., Nelson, W. G., Herman, J. G., and Davidson, N. E. (2001). Synergistic Activation of Functional Estrogen Receptor (ER)-alpha by DNA Methyltransferase and Histone Deacetylase Inhibition in Human ER-Alpha-Negative Breast Cancer Cells. Cancer Res. 61, 7025-7029.

Yaron, T., Cordova, Y., and Sprinzak, D. (2014). Juxtacrine Signaling Is Inherently Noisy. Biophysical J. 107, 2417-2424. doi:10.1016/j.bpj.2014.10.006

Yin, L., Duan, J. J., Bian, X. W., and Yu, S. C. (2020). Triple-negative Breast Cancer Molecular Subtyping and Treatment Progress. Breast Cancer Res. 22, 61-13. doi:10.1186/s13058-020-01296-5

Yu, T., Di, G., and Di, G. (2017). Role of Tumor Microenvironment in TripleNegative Breast Cancer and its Prognostic Significance. Chin. J. Cancer Res. 29, 237-252. doi:10.21147/j.issn.1000-9604.2017.03.10

Yuan, X., Wu, H., Xu, H., Xiong, H., Chu, Q., Yu, S., et al. (2015). Notch Signaling: an Emerging Therapeutic Target for Cancer Treatment. Cancer Lett. 369, 20-27. doi:10.1016/j.canlet.2015.07.048

Zeichner, S. B., Terawaki, H., and Gogineni, K. (2016). A Review of Systemic Treatment in Metastatic Triple-Negative Breast Cancer. Breast Cancer (Auckl) 10, 25-36. doi:10.4137/BCBCR.S32783

Zeinomar, N., Knight, J. A., Genkinger, J. M., Phillips, K. A., Daly, M. B., Milne, R. L., et al. (2019). Alcohol Consumption, Cigarette Smoking, and Familial Breast Cancer Risk: Findings from the Prospective Family Study Cohort (ProF-SC). Breast Cancer Res. 21, 128-214. doi:10.1186/s13058-019-1213-1

Zhang, Q., Liu, J., Ao, N., Yu, H., Peng, Y., Ou, L., et al. (2020). Secondary Cancer Risk after Radiation Therapy for Breast Cancer with Different Radiotherapy Techniques. Sci. Rep. 10, 1220-1312. doi:10.1038/s41598-020-58134-z

Zhang, X., Tworoger, S. S., Eliassen, A. H., and Hankinson, S. E. (2013). Postmenopausal Plasma Sex Hormone Levels and Breast Cancer Risk over 20 Years of Follow-Up. Breast Cancer Res. Treat. 137, 883-892. doi:10.1007/ s10549-012-2391-Z

Zhang, Y., Zhang, S., Zhang, Z., Ji, L., Zhang, J., Wang, Q., et al. (2021). Recent Progress on NIR-II Photothermal Therapy. Front. Chem. 9. doi:10.3389/fchem. 2021.728066

Zheng, H.-M., Chen, C., Wu, X.-H., Chen, J., Sun, S., Sun, J.-Z., et al. (2016). Quantum Dot-Based In Situ Simultaneous Molecular Imaging and Quantitative Analysis of EGFR and Collagen IV and Identification of Their Prognostic Value in Triple-Negative Breast Cancer. Tumor Biol. 37, 2509-2518. doi:10.1007/ s13277-015-4079-6

Zhou, L., Chen, B., Sheng, L., and Turner, A. (2020). The Effect of Vitamin D Supplementation on the Risk of Breast Cancer: a Trial Sequential MetaAnalysis. Breast Cancer Res. Treat. 182, 1-8. doi:10.1007/s10549-020-05669-4

Zhu, Y., Tian, Y., Du, J., Hu, Z., Yang, L., Liu, J., et al. (2012). Dvl2-dependent Activation of Daam1 and RhoA Regulates Wnt5a-Induced Breast Cancer Cell Migration. PLoS One 7, e37823. doi:10.1371/journal.pone.0037823

Conflict of Interest: The author declares that the research was conducted in the absence of any commercial or financial relationships that could be construed as a potential conflict of interest.

Publisher's Note: All claims expressed in this article are solely those of the authors and do not necessarily represent those of their affiliated organizations, or those of the publisher, the editors and the reviewers. Any product that may be evaluated in this article, or claim that may be made by its manufacturer, is not guaranteed or endorsed by the publisher.

Copyright (c) 2022 Almansour. This is an open-access article distributed under the terms of the Creative Commons Attribution License (CC BY). The use, distribution or reproduction in other forums is permitted, provided the original author(s) and the copyright owner(s) are credited and that the original publication in this journal is cited, in accordance with accepted academic practice. No use, distribution or reproduction is permitted which does not comply with these terms. 